\title{
Vulnerability of Kenya's Water Towers to Future Climate Change: An Assessment to Inform Decision Making in Watershed Management
}

\author{
Kenneth Kemucie Mwangi ${ }^{*}{ }^{(1)}$, Anthony M. Musili1, Viola A. Otieno' ${ }^{1}$, Hussen S. Endris ${ }^{1}$, \\ Geoffrey Sabiiti', Mohammed A. Hassan', Abebe Tadege Tsehayu', Artan Guleid1, \\ Zachary Atheru1, Alphonce C. Guzha'2, Thomas De Meo ${ }^{3}$, Nikola Smith ${ }^{3}$, \\ Dickson Lubanga Makanji ${ }^{4}$, John Kerkering5, Brehan Doud6, Enock Kanyanya ${ }^{7}$
}

${ }^{1}$ IGAD Climate Prediction and Applications Centre, Nairobi, Kenya

${ }^{2}$ USDA Forest Service, International Programs, c/o African Wildlife Foundation (AWF), Karen, Kenya

${ }^{3}$ USDA Forest Service, Pacific Northwest Region, Portland, OR, USA

${ }^{4}$ Egerton University, Njoro, Kenya

${ }^{5}$ USDA Forest Service, International Programs, Washington DC, USA

${ }^{6}$ USDA Forest Service, International Programs, Seattle, USA

${ }^{7}$ USAID Kenya and East Africa, Nairobi, Kenya

Email: *kmwangi@icpac.net

How to cite this paper: Mwangi, K. K., Musili, A. M., Otieno, V. A., Endris, H. S., Sabiiti, G., Hassan, M. A., Tsehayu, A. T., Guleid, A., Atheru, Z., Guzha, A. C., De Meo, T., Smith, N., Makanji, D. L., Kerkering, J., Doud, B., \& Kanyanya, E. (2020). Vulnerability of Kenya's Water Towers to Future Climate Change: An Assessment to Inform Decision Making in Watershed Management. American Journal of Climate Change, 9, 317-353.

https://doi.org/10.4236/ajcc.2020.93020

Received: August 21, 2020

Accepted: September 27, 2020

Published: September 30, 2020

Copyright $\odot 2020$ by author(s) and Scientific Research Publishing Inc. This work is licensed under the Creative Commons Attribution International License (CC BY 4.0). http://creativecommons.org/licenses/by/4.0/

\begin{abstract}
Recent trends show that in the coming decades, Kenya's natural resources will continue to face significant pressure due to both anthropogenic and natural stressors, and this will have greater negative impacts on socio-economic development including food security and livelihoods. Understanding the impacts of these stressors is an important step to developing coping and adaptation strategies at every level. The Water Towers of Kenya play a critical role in supplying ecosystems services such as water supply, timber and non-timber forest products and regulating services such as climate and water quantity and quality. To assess the vulnerability of the Water Towers to climate change, the study adopted the IPCC AR4 framework that defines vulnerability as a function of exposure, sensitivity, and adaptive capacity. The historical trends in rainfall indicate that the three Water Towers show a declining rainfall trend during the March-April-May (MAM) main rainy season, while the October-November-December (OND) short rainy season shows an increase. The temperature patterns are consistent with the domain having a common rising trend with a rate in the range of $0.3^{\circ} \mathrm{C}$ to $0.5^{\circ} \mathrm{C}$ per decade. Projection analysis considered three emissions scenarios: low-emission (mitigation) sce-
\end{abstract}


nario (RCP2.6), a medium-level emission scenario (RCP4.5), and a highemission (business as usual) scenario (RCP8.5). The results of the high-emission scenario show that the annual temperature over the Water Towers could rise by $3.0^{\circ} \mathrm{C}$ to $3.5^{\circ} \mathrm{C}$ by the $2050 \mathrm{~s}(2036-2065)$ and $3.6^{\circ} \mathrm{C}$ to $4.8^{\circ} \mathrm{C}$ by the 2070s (2055-2085 results not presented), relative to the baseline period 19702000. The findings indicate that exposure, sensitivity, and adaptive capacity vary in magnitude, as well as spatially across the Water Towers. This is reflected in the spatially variable vulnerability index across the Water Towers. Overall vulnerability will increase in the water towers leading to erosion of the resilience of the exposed ecosystems and the communities that rely on ecosystem services these landscapes provide.

\section{Keywords}

Kenya Water Towers, Climate Change, Vulnerability, Exposure, Sensitivity, Adaptive Capacity

\section{Introduction}

In the last decade, the concept of a "Water Tower" has gained prominence in Kenya. Water Towers refer to elevated landscapes, usually forested and are water catchment areas. Mau Forest Complex, Mt. Kenya, Aberdares, Cherangany Hills, and Mt. Elgon are the major Water Towers in the country and these are the main sources of many rivers in Kenya and feeding into major lakes, including Lake Victoria, Lake Turkana, Lake Baringo, Lake Nakuru, Lake Natron, and Lake Naivasha. Providing over 75\% of the country's water resources (GoK, 2013), the Water Towers are central to the economic and social well-being of the country. These ecosystems provide critical ecosystem services to the country including water, food, timber, wood, and honey, and regulating services (local climate regulation, water regulation, erosion regulation, water purification, disease regulation, and natural hazard regulation). These services are essential production factors in agriculture, forest, fishing, electricity, water supply, tourism, public administration, and defense factors. These sectors were reported to have contributed 33\% - 39\% to the country's gross domestic product (GDP) between 2001 and 2010 (UNEP, 2012b). A recent study undertaken by the Kenya Forest Research Institute (KEFRI) estimates that ecosystem services from the Mau, Cherangany and Mt Elgon Ecosystems have the potential to contribute at least $5 \%$ to Kenya's GDP. The mentioned sectors are important in Kenya for provision of both direct and indirect employment. All value chains in Kenya, in a way derive their basic inputs from land, and forestry plays an important role.

Like other ecosystems in the country, over the last few decades, the Water Towers have suffered increased degradation. For example, the Mau Forest has lost at least a quarter of the indigenous forest cover in the past few decades and this degradation has also occurred in Mt. Elgon and Cherangany Hills. Popula- 
tion increase and the demand for land, for settlements and agriculture, has led to this degradation of the Water Towers. In addition to these anthropogenic factors, climate change presents an additional threat to the integrity of these Water Towers. The adverse impacts of these threats on the Water Towers have direct impacts to the economy of Kenya. The continued degradation of these forests contributes to a growing water crisis. Perennial rivers are becoming seasonal, with further reduced dry season flows. Peak river discharges during the rainy seasons are also increasing leading to frequent downstream flooding. In some places, the yield of aquifers has dropped significantly, and springs have dried up. Emerging water "wars" between counties are an indication of the security and socio-economic upheavals that upsetting the integrity of the water supply system can result in.

The loss of biodiversity, increased carbon emissions from deforestation, and reduction in carbon sinks due to forest degradation are global—but also regional and national-concerns in terms of climate change effects, adaptation, and mitigation. Poor soil and water-resources conservation practices on deforested land contribute to soil erosion and decreasing crop yields. Changes in the microclimate and frequent droughts are affecting yields in commercial tea estates by causing fluctuating yields. A UNEP (2012a) technical report on Kenya's integrated forest ecosystem services highlighted both the value of Water Towers and the effects of deforestation. Between 2000 and 2010, deforestation in Kenya's Water Towers was estimated to be about 50,000 hectares. Nabutola (2010) asserted that during the past fifteen years, more than 100,000 hectares-about a quarter of the protected forest reserve in the Mau Forest-had been cleared and settled on. The net cumulative effect of deforestation resulted in a loss of USD 68 million from the economy in 2010 (UNEP, 2012a).

Numerous challenges resulting from climate change pose significant threats to development (Thornton et al., 2014). A United States Agency for International Development report (2012) projected significant fluctuations of rainfall amount and seasons throughout the year, with increased inter-annual variability. Climate projections from climate models indicated an increase in the frequency and duration of drought, and an increase in precipitation observed during heavy rainfall events. The National Adaptation Plan, 2015, stated that there would be an increasing climate effect on average rainfall during the short rainy season (October to December). The proportion of annual rainfall occurring during heavy rainstorms is also expected to increase. According to general circulation model (GCM) data, the increase could range from $2 \%$ to $11 \%$ by the 2060 s and 2 to 12 percent by the end of the century. The mean annual temperature is projected to increase by $0.8^{\circ} \mathrm{C}$ to $1.5^{\circ} \mathrm{C}$ in the 2030 s and $1.6^{\circ} \mathrm{C}$ to $2.7^{\circ} \mathrm{C}$ in the 2060 s. Boko et al. (2007) suggested increased temperatures were likely to be exacerbated by trends in land-use changes (mostly deforestation), further undermining the resilience of habitats, ecosystems, and species.

Such stresses in the Eastern African region, including severe and prolonged droughts-such as those seen in 2000-2001, 2010-11, and 2016-17-demonstrate 
the sensitivity and vulnerabilities of local populations. More than 10 percent of the region's population is gradually becoming chronically food insecure, requiring both short-term emergency food relief and sustainable long-term development programs. For livestock and wildlife herds, the recurrent extreme climatic events with insufficient recovery periods are pushing pastoral economies and livelihoods to the brink of collapse (Funk et al., 2017). With predicted increases in the magnitude of these effects there is a need for improved understanding of the full range of climate change impacts on ecological and socioeconomic systems in order to address the effects of climate variability and change on both humans and ecosystems (Thornton et al., 2014). Climate change is a direct driver affecting the functioning of the Water Tower ecosystems, therefore, an assessment of the vulnerability of the ecosystems has a direct relationship to the economic values of environmental services derived from these ecosystems which include biodiversity, climate regulation, soil regulation and water regulation and as outlined by Howe et al., 2013, these services have intimate relationship to economic development, manufacturing, food security and health.

A key challenge associated with climate change is that it is no longer possible to rely only on knowledge of the past weather patterns to guide planning for the future. The continuous changes observed in climate patterns means that adaptive planning will be important to cope with the expected climate perturbations. The objective of this study was to quantitatively assess the vulnerability of the three Waters Towers to climate change. To achieve this goal, the following questions guided this study:

1) What are the current and expected future climate risks in the Water Tower ecosystems?

a) By what magnitude, if any, will temperatures (maximum and minimum) change?

b) By what magnitude, if any, will precipitation change?

2) What are the current and projected vulnerabilities of the Water Towers? How does climate change impact the following;

a) Water Resources

b) Forests?

This CCVA therefore contributes to our understanding of current and projected climate trends (exposure), effects (sensitivity), and adaptive capacity (vulnerabilities) in the major Water Tower ecosystems. The CCVA is expected to guide the development of adaptation measures, which are based on an understanding of:

1) the likelihood and extent (magnitude) of change,

2) the vulnerability of specific sectors to the predicted change, and

3) the local-scale possibilities for adaptation.

\section{Methods}

\subsection{Study Area}

The three Water Towers fall within 34.2- and 36.5-degrees East longitudes and 
1.6 degrees North and 1.2 degrees South latitude (Figure 1). The analysis was done on pixel level, at 1-kilometer spatial resolution. While the finest data used in the analysis had 30-meter spatial resolution, the coarsest had 5-kilometer spatial resolution. Resampling was necessary to have all layers at a common spatial resolution of 1 kilometer and the data used for this assessment were projected to the World Geodetic System 1984 to enable interoperability.

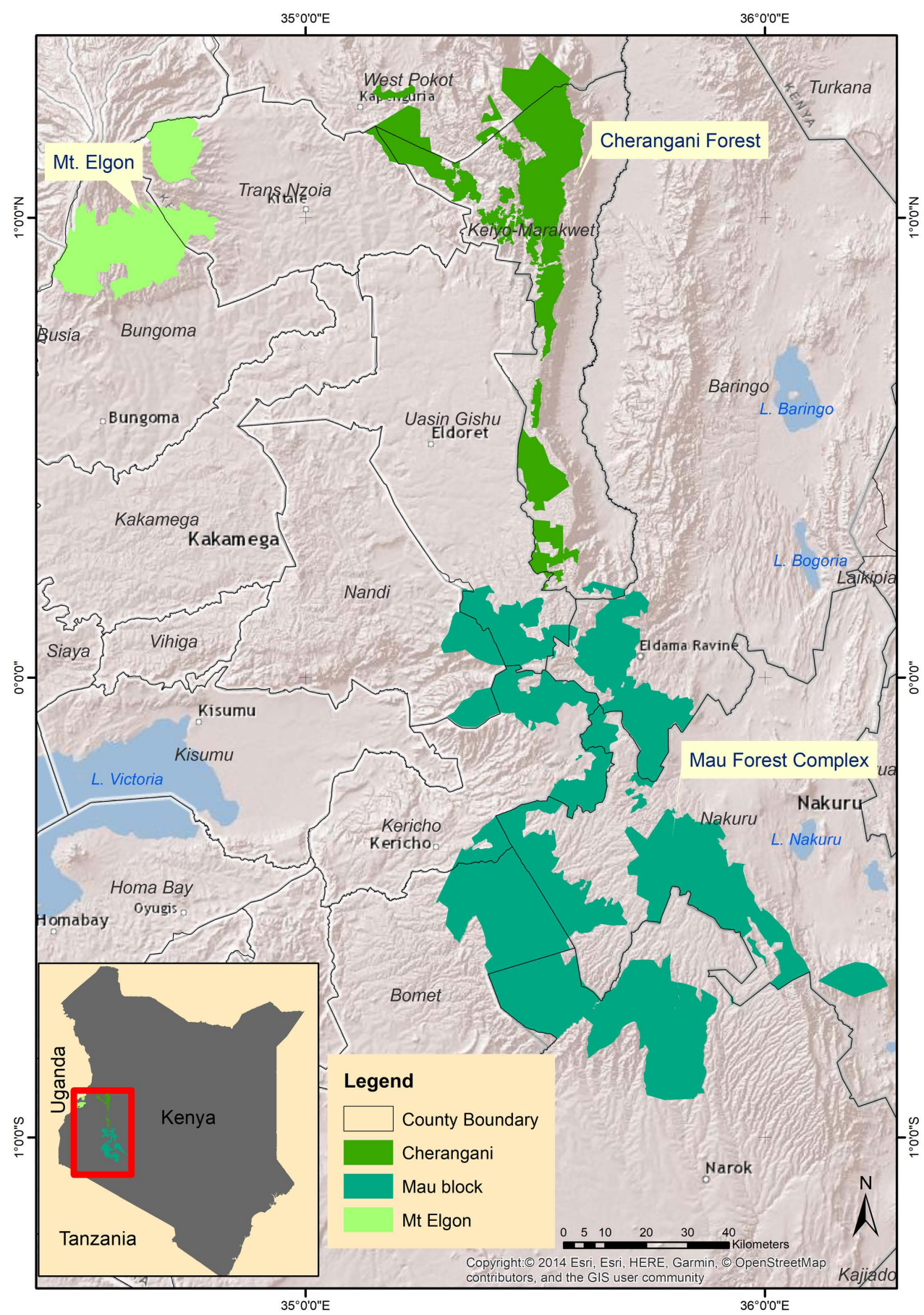

Figure 1. Location of Mau complex, Cherangany hills and Mt Elgon ecosystems (Source: ICPAC and SRTM). 


\subsubsection{Mau Forest Complex}

The Mau Forest Complex is Kenya's largest closed-canopy forest ecosystem, consisting of 22 forest blocks and an area of 404,706 hectares. The forest area includes part of Nakuru, Baringo, Kericho, Narok, Bomet, Nandi, and Uasin Gishu counties, and it comprises indigenous forests, plantations, glades, and bamboo (KWTA, 2015). It serves as the upper catchment area of several rivers including Nyando, Sondu, Mara, Kerio, Molo, Ewaso Ngiro (South), Njoro, Nderit, Makalia, and Naishi. The forest complex also feeds major lakes, including Lake Victoria, Lake Natron, Lake Nakuru, and Lake Baringo, some of which are transboundary. As a result, Mau Forest Complex is considered important both regionally and internationally (UNEP and GoK, 2012). Rivers originating from the Mau Complex are a lifeline for major tourism destination areas, including Maasai Mara National Reserve and Lake Nakuru National Park. These parks generate significant revenue for the Kenyan economy. These rivers from the Water Towers support habitats and conservation sites that are globally identified as Important Bird and Biodiversity Areas (IBA's) around Lake Baringo and Lake Natron (UNEP, 2008). The GoK and UNEP (2008) approximated the potential of hydropower generation from Mau ecosystem rivers to be about 535 megawatts (MW). Due to the ecological and socio-economic services it provides, the Mau Complex is the most important water catchment in the Rift Valley and Western Kenya. Through its ecological services, the Mau ecosystem supports key economic sectors in Kenya, including forestry, energy, tourism, agriculture, and water supply.

\subsubsection{Mt. Elgon}

Mt. Elgon is a transboundary ecosystem (Uganda and Kenya) covering an area of 236,505 hectares in Kenya's Bungoma and Trans Nzoia counties. It is an extinct volcano, rising to 4321 meters above mean sea level and is the source of the Nzoia River, which flows to Lake Victoria, and Turkwel River, which drains into Lake Turkana. The area has a bi-modal rainfall pattern averaging 1270 mm annually occurring between March-June and latter rains August-October (KWTA, 2019). The ecosystem is mainly a mixed montane forest, comprising of at least four ecological zones characterized by different vegetation communities, namely: mixed montane forest, bamboo and low canopy forest, sub-alpine montane heath and alpine moorland. The forest is an important regional resource that supports local economies through direct and indirect uses and is a significant carbon sink to mitigate climate change. The Mt. Elgon ecosystem is habitat to thirty-seven "globally threatened" species-twenty-two mammal, thirteen birds, and two insect species and is home to nine endemic animals (KWTA, 2019).

\subsubsection{Cherangany Hills}

The Cherangany Hills is a collection of thirteen forest reserve blocks on the western ridge of the Great Rift valley. The forests encompass an area of approx- 
imately 120,000 hectares and form part of the upper catchment of the Nzoia, the Kerio, and Turkwel rivers. The Cherangany Hills rise to heights of 3000 meters above mean sea level and support unique afro-alpine vegetation. Cherangany Hills are also home to the rare and endangered De Brazza's monkey. The Cherangany Hills ecosystem supports major conservation areas which include: Saiwa Swamp National Park (known for the endangered antelope species-Sitatunga), South Turkana National Reserve, Rimoi Game Reserve and Kerio Valley National Reserves (FPP, 2014). The Water Tower is transboundary, encompassing parts of Elgeyo Marakwet, West Pokot, Trans Nzoia, Baringo, and Uasin Gishu counties.

\subsubsection{Vulnerability Assessment Method}

There are several methodologies and approaches that have been used in assessing climate change vulnerability (Carlos \& Yoon, 2015; PROVIA, 2013; de Sherbinin, 2014). The methodology employed in this study is the spatial indices approach, which implements the IPCC AR4 conceptual framework definition of vulnerability as a function of exposure, sensitivity, and adaptive capacity (Glick et al., 2010; Roy \& Blaschke, 2015; Weis et al., 2016).

Climate Change Vulnerability $=f($ Exposure, Sensitivity, and Adaptive Capacity $)$

The spatial indices approach aggregates, through various techniques, several datasets that have been identified to be indicators of exposure, sensitivity, and adaptive capacity (GIZ, 2014; PROVIA, 2013). An indicator is defined as a single measure of an attribute, such as mean temperature, while an index is defined as an aggregate or measure of several indicators or indices (Roy \& Blaschke, 2015). Spatial grids of 1 kilometer were used as the unit of analysis. A grid-based rather than boundary-based approach has the advantage of not suffering from the common spatial analysis problem-the modifiable areal unit problem (Roy \& Blaschke, 2015).

Several studies reviewing methodologies of spatial vulnerability assessment have highlighted four common techniques of aggregating indicators to develop indices (Moret, 2014; PROVIA, 2013; de Sherbinin, 2014). The four techniques are additive/averaging, which can further be categorized into weighted or simple additive/averaging, principal component analysis, cluster analysis, and geons (Kienberger et al., 2009). Each of the four techniques has pros and cons. The additive technique is used in this study to develop the vulnerability indices. It is widely accepted that different attributes or indicators have varying magnitudes of effects on the vulnerability of a system, however, in the absence of a reliable standardized measure of effects, assigning equal weights is justified as a way of simplification (Kienberger et al., 2009; de Sherbinin, 2014). Most studies incorporating weights, as highlighted by de Sherbinin (2014), use expert knowledge to decide and justify the weight assigned to each indicator or index against the attribute being investigated. Carlos \& Yoon (2015) noted that different studies show different results because of weight assignment and the ad-hoc assumptions 
made on the relationship between indicators and their contribution to vulnerability to climate variability and change.

In this assessment, a list of indicators shown Figure 2 for each of the three components (exposure, sensitivity, and adaptive capacity) was identified through expert and stakeholder involvement. The relevant datasets providing proxies for the listed indicators were identified and acquired from various sources. The reliability and validity of the datasets were analyzed. Due to the varying units of measurements between the indicators-for instance, millimeters for average rainfall and degrees Celsius for average temperature-each of the indicators and sub-indices were normalized before summation to ensure all indicators are on a standardized unitless scale of 0 to 100 to allow for effective comparisons. Using the range standardization method (Willis \& Fitton, 2016), the least vulnerable is represented by 0 , while 100 represents the highest vulnerability. It was necessary for some indicators, such as adaptive capacity indicators, to inverse the scale, since a high level of adaptive capacity means less vulnerability and vice versa. The normalization approach is considered standard practice and it has been used in various studies, though the chosen scale varies (de Sherbinin et al., 2014; Willis \& Fitton, 2016). The indicators are un-weighted, meaning each indicator is assumed to have equal contributions to the component to which it contributes. Similar approaches have been employed by de Sherbinin et al. (2014) and Weis et al. (2016). However, studies by Willis \& Fitton (2016) applied weights to the indicators. Community appraisal was used in the validation of indicators and indices. The sensitivity and adaptive capacity indicators were ranked, using expert knowledge, into five classes based on their impact or severity of vulnerability.

\subsection{Exposure Attributes}

In this study, climate exposure attributes were used and projected changes in

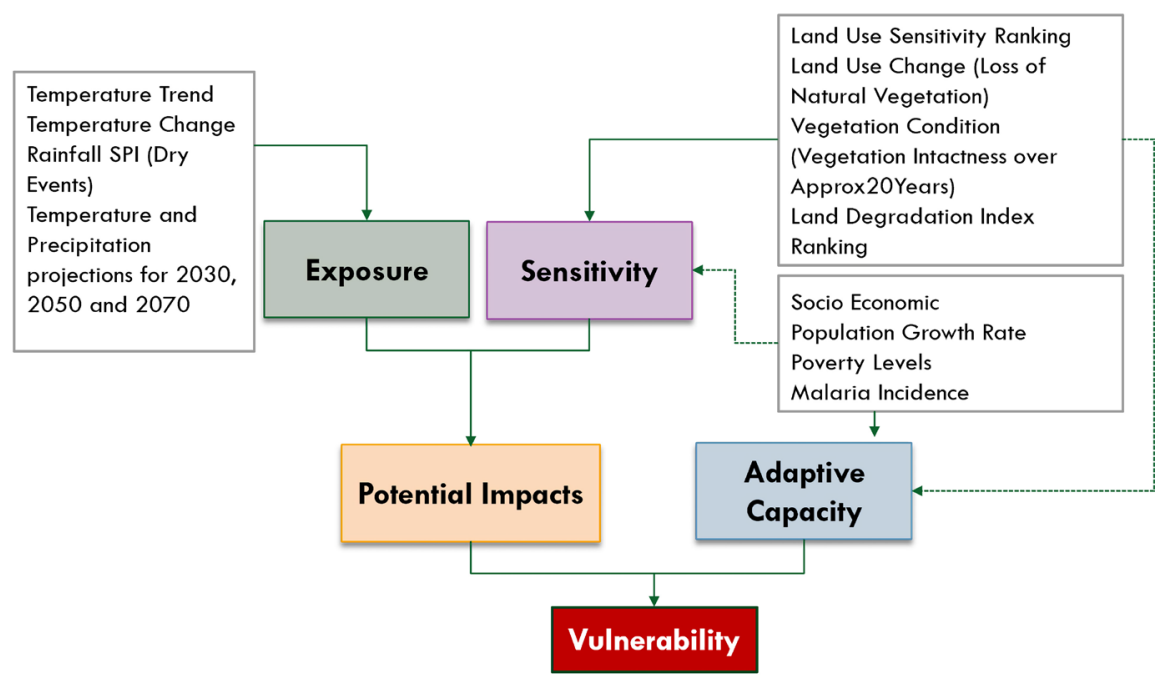

Figure 2. Framework/methodology of the assessment. 
climate were based three on representative concentration pathways- $\mathrm{RCP} 8.5$, 4.5 and 2.6. Based on the availability of data, the period for this study's analysis was set as 1981-2010. This thirty-year period is considered the baseline against which future time periods (scenarios) will be assessed. The future periods were defined as Near Future (NF): 2016-2045; Mid Future (MF): 2036-2065 and Far Future (FF): 2056-2085.

\subsubsection{Climate Data}

Historical climate data and climate projections were used to assess the observed and projected climate trends and changes over the three Kenya Water Towers. Station data for the rainfall, maximum temperature, and minimum temperature variables for Eldoret, Kitale, Kitale, and Kericho meteorological stations were used. Rainfall data collected at Aroket Tea Estate, Egerton University (Njoro), Sabatia Forest, and Kuresoi Forest station were also used. The data were obtained from the Kenya Meteorological Department (KMD). Gridded rainfall data from the Climate Hazards Group Infrared Precipitation with Stations (CHIRPS) at 0.05-degree resolution (Funk et al., 2015) were obtained for the years 1981-2015. This dataset was further blended with the in-situ observations obtained from KMD to obtain a representative dataset for the region. For temperature, a gridded dataset was obtained from the Climatic Research Unit (CRU) at the University of East Anglia. This is a gauge-based gridded dataset (CRU TS3.24.01) available at 0.5-degree spatial and monthly temporal resolutions for the years 19012015. The data were re-gridded at a 0.05 -degree resolution and used for analysis for the years 1981-2015. In addition to the CRU dataset, gridded temperature data from the U.S. National Oceanic and Atmospheric Administration (NOAA) and the National Centers for Environmental Prediction (NCEP) were used to estimate potential ET at daily timescale. This dataset was produced using observed daily temperature data reported through the World Meteorological Organization's Global Telecommunication System. The grid spatial resolution was 0.5 degrees. Using the Blaney-Criddle equation, the potential ET was calculated based on guidelines in the Food and Agriculture Organization (FAO) technical paper (Doorenbos and Pruitt, 1977), and eventually the real average daily ET was produced.

Regional climate model outputs generated for future time periods from the Coordinated Regional Climate Downscaling Experiment-CORDEX (Giorgi et al., 2009) have been used. The model used for this study is the Rossby Centre regional atmospheric model (RCA4), driven by lateral boundary conditions from the Earth system version of the Max Planck Institute for Meteorology (MPIESM-LR) coupled global climate model. The horizontal grid spacing of the simulation is 0.44 degrees (about 50 kilometers). For the purpose of the CCVA, the simulated data are interpolated to 5-kilometer resolution. The choice of the RCA model driven by MPI-ESM-LR for this analysis was based mainly on the availability of the model outputs for the three different scenarios (RCP2.6, RCP4.5, and RCP8.5), since the other model runs were available for only one or two of 
the three scenarios. Moreover, a recent study (Endris et al., 2015) has shown that the RCA model run driven by MPI-ESM-LR better reproduces the large-scale signals, such as the El Niño-Southern Oscillation and the Indian Ocean Dipole, in the historical period over the Eastern Africa region than RCA model runs driven by the other global climate models. The model has been run for the historical period covering the years from 1951 until 2005 and the future projection covering the years from 2006 up to 2100 . The historical simulations are forced by observed natural and anthropogenic atmospheric composition, whereas the projections are forced by the Representative Concentration Pathways (RCP's). The RCP's represent approximate total radiative forcing values in $\mathrm{W} / \mathrm{m}^{2}$ for the year 2100 relative to 1750 in the range of $2.6-8.5 \mathrm{~W} / \mathrm{m}^{2}$ (Moss et al., 2010). In this report, climate projections under three RCPs are used, namely RCP2.6, RCP4.5, and RCP8.5, which represent the low-, mid-, and high-level emission and concentration scenarios respectively. The RCP2.6 emission and concentration pathway, also referred to as $\mathrm{RCP} 3 \mathrm{PD}$, represents a peak in radiative forcing at $\sim 3 \mathrm{~W} / \mathrm{m}^{2}\left(\sim 490 \mathrm{ppm} \mathrm{CO} \mathrm{CO}_{2}\right)$ by the mid-twenty-first century and then a decline to a low forcing level of $2.6 \mathrm{~W} / \mathrm{m}^{2}$ by 2100 . This scenario assumes strong greenhouse gas (GHG) mitigation actions and that the increase in the global average temperature will be limited below $2^{\circ} \mathrm{C}$. RCP4.5 is a medium-level concentration pathway assuming stabilized radiative forcing at $4.5 \mathrm{~W} / \mathrm{m}^{2}\left(\sim 650 \mathrm{ppm} \mathrm{CO}_{2}\right)$ and that this value will not be exceeded by the year 2100 . In contrast, the RCP8.5 pathway represents a high-concentration pathway in which radiative forcing is assumed to reach $8.5 \mathrm{~W} / \mathrm{m}^{2}$ by the year $2100\left(\sim 1370 \mathrm{ppm} \mathrm{CO}_{2}\right)$ and then continue to rise thereafter. The RCP8.5 socioeconomic pathway is characterized by a rapidly rising population and relatively slow income growth with modest rates of technological change and energy-intensity improvements, leading to high-energy demands and GHG emissions in the absence of climate change policies (Riahi et al., 2011).

\subsubsection{Climate Data Analysis}

Different statistical methods have been used to assess the observed and projected trends and changes in rainfall and temperatures in the three Water Towers, as well as for generating climate indicators that will be used as input layers for assessing climate change vulnerability. Averages, trends, the Standardized Precipitation Index (SPI), and changes or anomalies have been computed for different seasons [annually, June-July-August-September (JJAS), March-April-May (MAM), and October-November-December (OND)]; for the historical period; different future time slices (2030s, 2050s, and 2070s); and different scenarios (RCP2.6, 4.5, and 8.5).

A thirty-year average is usually the standard period to consider when determining the climatology of a region. In the current study, the years 1981-2010 were taken as the baseline. The trends were used to detect the long-term rates of change for both temperature and rainfall. The Standardized Precipitation Index (SPI) is an index based on anomalous rainfall and is useful for the spatial and 
temporal analyses of drought events (Livada \& Assimakopoulos, 2006). SPI values can be interpreted as the number of standard deviations by which observed rainfall deviates from long term mean. The SPI series for spatially averaged patterns in the three Water Towers were analyzed to detect the patterns of drought events over time.

SPI was selected as one of the key climate indicators for mapping the climate change vulnerability of the Water Towers. It is the most commonly used Index to measure how drought affects a region. Positive SPI values indicate wet conditions while negative SPI values indicate dry conditions. SPI can be calculated at three, six, twelve, twenty-four, and forty-eight-month time scales based on the available precipitation data. For this analysis, the projected frequencies of twelve-month SPI for a given threshold have been computed and analyzed for two future time slices 2030s (2016-2045) and 2050s (2036-2065) to provide information on the expected magnitude of abnormally wet and dry periods over each time window. The frequencies of twelve-month SPI Indices were calculated based on SPI time series for wet and dry phases/events. A threshold of SPI value of \pm 1 has been used to compute the frequency of SPI for wet and dry phases over 30 years. It means, the frequency for wet (dry) periods is defined when twelvemonth SPI value is higher (lower) than $+1(-1)$ for each grid cell.

\subsection{Sensitivity Attributes}

As outlined by McCarthy et al. (2001), sensitivity is the degree to which a system is affected, either adversely or beneficially, by climate-related stimuli. The effects can be direct (e.g. forest productivity change in response to a change in the mean, range or variability of rainfall) or indirect (e.g. damages to forest stock caused by an increase in the frequency of droughts. Five biophysical indicators were identified and used in modelling the sensitivity component of the vulnerability assessment of the water towers. The Water Requirement Satisfaction Index was applied with respect to maize-a staple crop in Kenya. The study used land cover datasets for 1995 and 2014 (Figure 3) obtained from the Regional Centre for Mapping of Resources for Development (RCMRD). The data included wall-to-wall mapping of land cover in Kenya using Landsat satellite images at 30-meter spatial resolution from 1990 to 2014 within the dry season. The random forest classifier was used to develop ten land-cover classes. Land-cover mapping was done at the minimum mapping unit of 0.5 hectares.

$$
\begin{aligned}
\text { Sensitivity }= & f(\text { Vegetation Intactness, Land Cover Change, } \\
& \text { Land Cover Sensitivity, Land Degradation Index, } \\
& \text { Water Requirement Satisfaction Index })
\end{aligned}
$$

\section{Vegetation Intactness}

The Vegetation Condition Index (VCI) was used to compute vegetation intactness, which represents how unchanged vegetation has been in the water towers over the years. A changing VCI indicates the effects of anthropogenic interference 


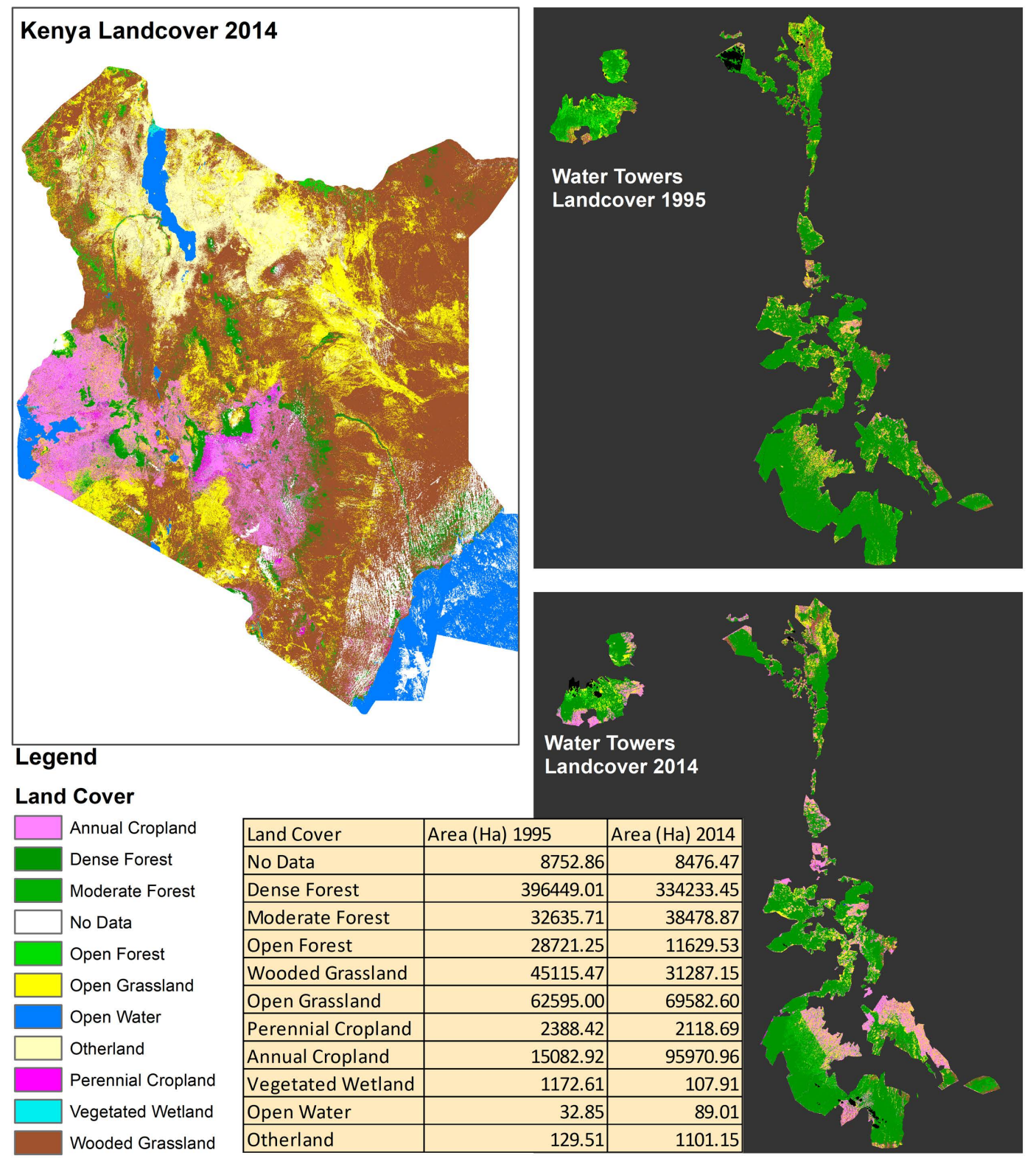

Figure 3. Land use and land cover map (Source: RCMRD, 2015).

or climate-change effects on the vegetation cover. VCI is a pixel-wise normalization developed to control local differences in ecosystem productivity. VCI is useful in making relative assessments of changes in the vegetation index signal by filtering out the contribution of local geographic resources to the spatial variability of vegetation (Jiao et al., 2016). This makes VCI useful in evaluating the water towers, where the vegetation index varies from high values in evergreen forests to low values in seasonal grasslands, with low vegetation index values and varying geographic terrains.

The VCI is computed as:

$$
\mathrm{VCI}=\frac{\mathrm{NDVI}-\mathrm{NDVI}_{\min }}{\mathrm{NDVI}_{\max }-\mathrm{NDVI}_{\min }}
$$


where:

$\mathrm{VCI}=$ Vegetation Condition Index at ten-day intervals

NDVI $=$ Normalized Difference Vegetation Index

$\mathrm{NDVI}_{\max }=$ Highest-ranking value observed from 1999 to 2015 at ten-day intervals

$\mathrm{NDVI}_{\min }=$ Lowest-ranking value observed from 1999 to 2015 at ten-day intervals

The Normalized Difference Vegetation Index (NDVI) was used to compute the VCI. NDVI was obtained from PROBA V and SPOT VGT satellite data sources. It is a computation of a ten-day data maximum value composite image as shown in Figure 4 below.

\subsection{Adaptive Capacity}

The Intergovernmental Panel on Climate Change defined adaptive capacity as the potential for a system to respond to environmental change to mitigate negative environmental impacts (IPCC, 2014). To estimate the adaptive capacity of the water-tower ecosystems, three socio economic indicators for communities living adjacent and within these landscapes were selected-poverty, population growth, and malaria incidence. The three indicators have an inverse relationship with the ecosystems' capability to cope or adapt to changes and variability in climate. High rates of all three indicators indicate the low capability of the ecosystems to cope or adapt to climate change and variability.

\subsection{Vulnerability of Water Resources}

\subsubsection{River Discharge, Water Use and Abstraction}

In this assessment, a hydrologic modeling approach was used to predict this vulnerability. A dataset of discharge from twenty-one rivers was procured from the Kenya Water Resources Authority (WRA). This represents all available river-gauging station data for the study area during the years 1981-2010. The river discharge data were naturalized by adding the water abstracted or diverted upstream of each station. Water-abstraction permit data were also procured for the study basins to provide information on the amount permitted for abstraction from each basin and sub-basin. These data were used to naturalize the river flows and assess the effect of river-flow variability and change due to climate change.

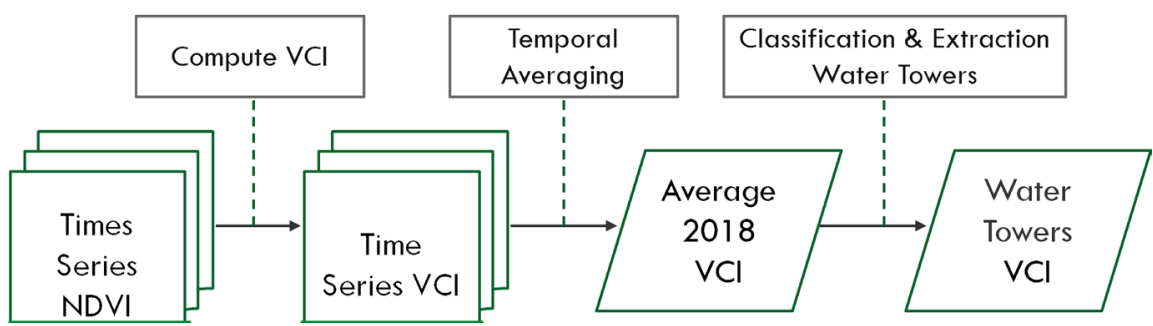

Figure 4. Vegetation condition index (VCI) computation. 
The MIKE Hydro rainfall runoff model was used for this assessment and the results from the simulations for future climate scenarios can be used as references for climate change mitigation and adaptation, and for water resource planning and management. To understand the impacts of climate changes on watershed hydrology, the following steps were taken:

1) Processing the RCA4 climate model outputs to extract precipitation and temperature data for the three scenarios (RCP 2.6, 4.5, and 8.5) for the years 1981-2100.

2) Estimating the Delta-change factors for three future periods, the "near future" (2016-2045), "mid-future" (2036-2065), and the "far future" (2056-2085), using 1981-2010 as the reference period.

3) Setting up a MIKE HYDRO/Nedbør Afløbs Model (NAM) rainfall runoff model for the fifty-nine catchments in twelve basins.

4) Calibrating and validating the MIKE HYDRO/NAM model using gridded, remotely sensed, and observed hydro-meteorological data as well as water abstraction data for the period 1981-2010.

5) Producing new input data for the three scenarios and three future periods using the remotely sensed or observed data and Delta-change factors. This makes nine input datasets.

6) Running the calibrated and validated MIKE HYDRO/NAM model using the nine datasets for the three scenarios and three future periods as input data.

7) Assessing the results on key hydrological parameters-discharge, flow regimes and water deficit.

\subsubsection{The Study Area Watersheds}

There are twelve basins with tributaries emanating from the three Water Tower ecosystems. These rivers flow to the inland lakes of Baringo, Bogoria, Natron, Turkana, and Victoria. The basins and their tributaries were delineated using 30-meter Digital Elevation Model (DEM) at river-discharge gauge locations. The delineation was done using the MIKE HYDRO software and produced fifty-nine catchments for the river basins of Ewaso Ngiro (South), Gucha-Migori, Kerio, Lake Baringo, Malaba-Malakisi, Mara, Nzoia, Nyando, Sio, Sondu, Turkwel, and Yala. Fifty-nine catchments representing twelve river basins were delineated as the first step in setting up the model. The MIKE HYDRO model's catchment delineation module was used with a 30-meter DEM. Baseline input time series (precipitation and ET) were prepared for each catchment and data loaded into MIKE HYDRO. Model calibration involves adjusting model catchment parameters until a good fit between the model catchment runoff and observed river flow is achieved. In the case of the NAM model, the adjusted parameters are shown in Table 1.

\section{Results}

\subsection{Baseline Climatology}

Understanding the climate of a given location forms the basis of objective analysis 
Table 1. Nedbør Afløbs model adjusted parameters.

\begin{tabular}{|c|c|c|}
\hline \multicolumn{3}{|c|}{ Adjusted Parameters } \\
\hline Parameter & Description & Effects \\
\hline Umax & $\begin{array}{l}\text { Maximum water content in surface } \\
\text { storage }\end{array}$ & $\begin{array}{l}\text { Overland flow, infiltration, evapotranspiration, } \\
\text { interflow }\end{array}$ \\
\hline Lmax & $\begin{array}{l}\text { Maximum water content in root } \\
\text { storage }\end{array}$ & $\begin{array}{l}\text { Overland flow, infiltration, evapotranspiration, } \\
\text { base flow }\end{array}$ \\
\hline CQOF & Overland flow coefficient & Volume of overland flow and infiltration \\
\hline CKIF & Interflow drainage constant & Drainage of surface storage as interflow \\
\hline TOF & Overland flow threshold & $\begin{array}{l}\text { Soil moisture demand that must be satisfied for } \\
\text { overland flow to occur }\end{array}$ \\
\hline TIF & Interflow threshold & $\begin{array}{l}\text { Soil moisture demand that must be satisfied for } \\
\text { interflow to occur }\end{array}$ \\
\hline TG & Groundwater recharge Threshold & $\begin{array}{l}\text { Soil moisture demand that must be satisfied for } \\
\text { groundwater recharge to occur }\end{array}$ \\
\hline CK1 & Timing constant for overland flow & $\begin{array}{l}\text { Routing overland flow along catchment slopes } \\
\text { and channels }\end{array}$ \\
\hline CK2 & Timing constant for interflow & Routing interflow along catchment slopes \\
\hline $\mathrm{CKBF}$ & Timing constant for base flow & $\begin{array}{l}\text { Routing recharge through linear groundwater } \\
\text { recharge }\end{array}$ \\
\hline
\end{tabular}

on climate change and related vulnerabilities. In this regard, an analysis was done to capture the spatial and temporal patterns of the rainfall and temperature, as well as the Standardized Precipitation Index (SPI). The average rainfall in the three Water Towers ranges from below $200 \mathrm{~mm}$ to more than $1500 \mathrm{~mm}$. In comparison to the whole country, regions in the three Water Towers receive the highest rainfall amounts in Kenya-above $1000 \mathrm{~mm}$ per year. The MarchMay (long rains) season has the highest rainfall amounts, while the DecemberFebruary season receives the least rainfall in the Water Towers. Although the larger equatorial East Africa region has a bimodal rainfall pattern, with the long rains in March-May and short rains in October-December, the Water Towers have a trimodal rainfall pattern. The winter months of June-August also form an active rainfall season. In terms of rainfall amounts, the June-August season is superior to the October-December season. Based on the historical rainfall data for three stations, the Mau complex is the wettest, followed by Mt. Elgon and then Cherangany. Based on the SPI time series on annual timescale analysis (Figure 5), all three of the water towers show uniformity in the pattern of dry and wet events. However, the severity of these events varies between the water towers.

Long-term temperature averages and annual cycles show that Mau experiences lower average temperature compared to Mt Elgon and Cherangany. Maximum temperatures are highest in February and lowest in July. In contrast, the highest minimum temperatures are in April, and the lowest minimum temperatures are in September. Higher maximum temperatures imply a greater risk of drought, with adverse effects on crop production and water supplies. The low 


\section{Mau}

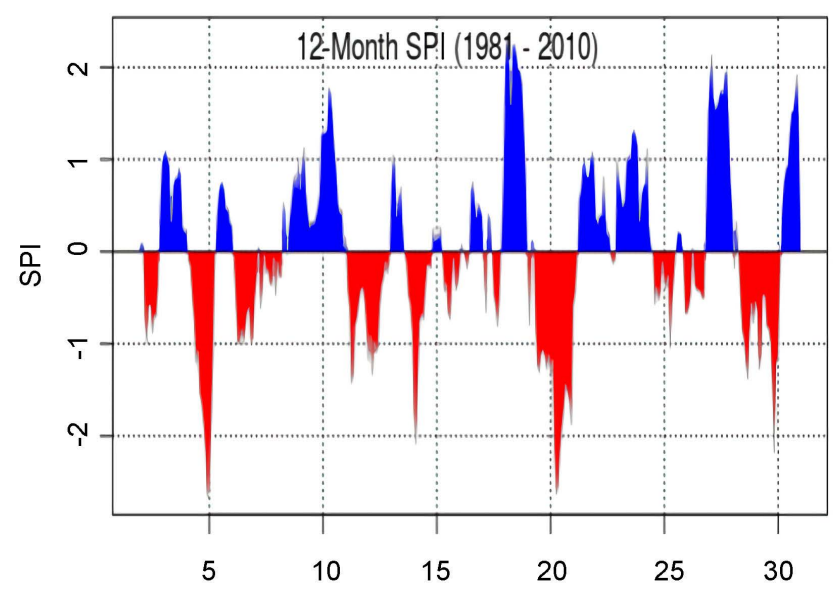

Mt. Elgon

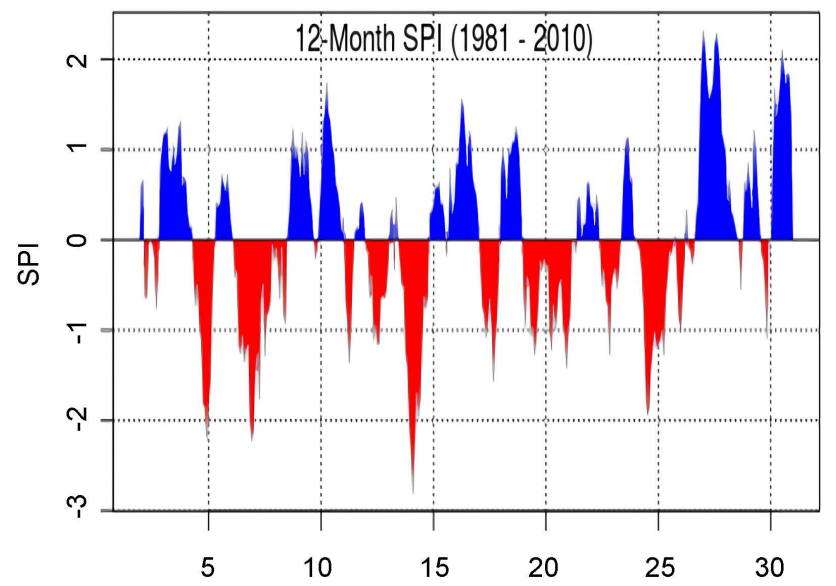

\section{Cherangany}

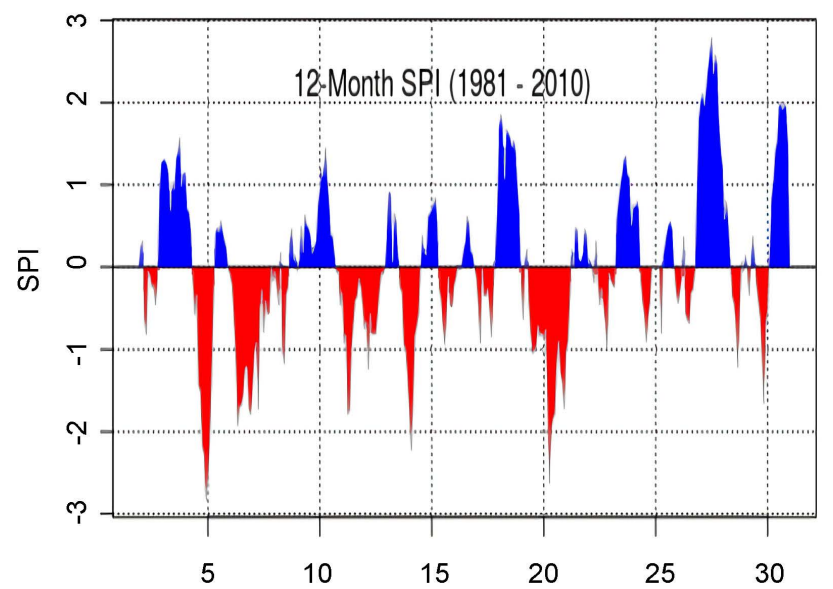

Figure 5. Twelve-month standardized precipitation index (SPI) in the historical period (1981-2010) over the three water towers.

temperature microclimate in the Mau area supports large- and small-scale commercial tea enterprises. Higher minimum temperatures also imply a greater risk of insects and diseases, since they can be temperature driven and constrained by cooler temperatures (Luck et al., 2011). These temperature variations coincide with the annual latitudinal oscillation of the sun but are being altered by climate change. Frost incidence over the Water Towers-especially in the highlands of Nandi, Kericho, Kisii, and Bomet, have increased (Bore, 2015).

\subsection{Historical Climate Trends}

Annual and seasonal rainfall trends over the three Water Towers show a dominant declining rainfall is observed in MAM over all the Water Towers (Figure 6). In addition, JJAS has a declining trend over Mau but an increase over Mt. Elgon and Cherangany ecosystems. With declining trends for both MAM and JJAS seasons, the major crop season of March to November (for maize) has progressively been put under strain. On the other hand, the OND season has an 

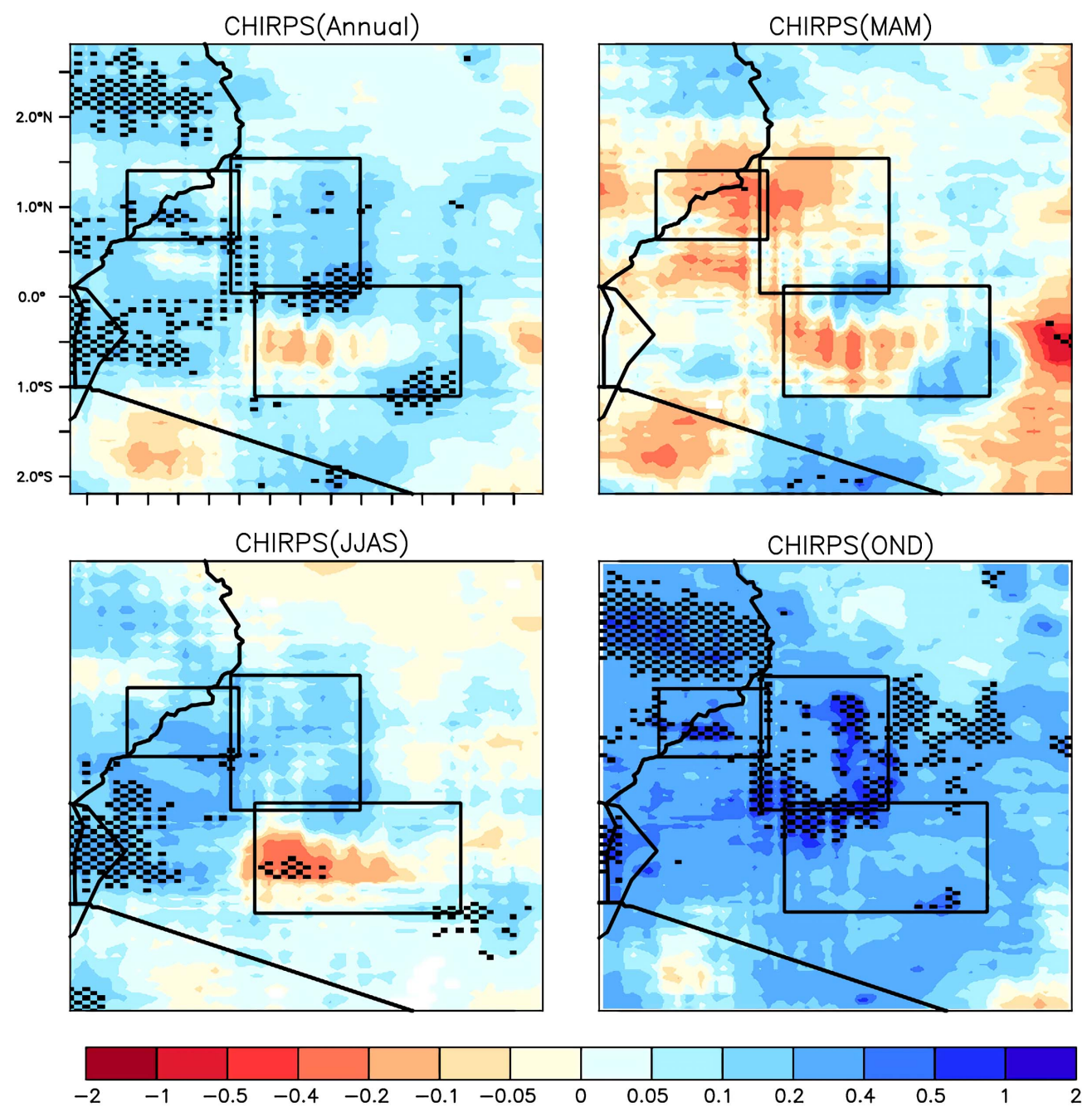

Figure 6. Rainfall trends over the three Kenya Water Towers (millimeters/day/decade).

increasing trend of rainfall over all the Water Towers. This increase tends to compensate for rainfall declines in the other season, such that the total annual pattern has an increasing trend, save for Mau. Over the Mau Complex, the decline in annual rainfall is about $36.5 \mathrm{~mm}$ in a decade. This observation is consistent with other climate-trend work done in East Africa (e.g. Tierney et al., 2015).

Increasing temperature trends are consistent for the maximum, average, and minimum temperatures over the Water Towers. In addition, the range of increase is consistent at 0.3 to 0.5 degrees per decade. This implies that, over the past thirty years, the region has warmed by about $0.9^{\circ} \mathrm{C}$ to $1.5^{\circ} \mathrm{C}$. However, the warming rate of minimum temperatures is higher for the Mau ecosystem than for Mt. Elgon and Cherangany. The minimum temperature has a consistent increasing trend-unlike the maximum temperature, which has marked variability.

\subsection{Projected Changes in Rainfall and Temperature}

The projected changes in rainfall, maximum temperatures, and minimum tem- 
peratures based on the RCP2.6 and RCP4.5, scenarios have been analysed for future time slices-2030s (2016-2045), 2050s (2036-2065) and 2070s (2056-2085) (whose results are not represented), to provide information on the expected magnitude of the climate response over each time window. The time period of 1971-2000 is considered as a baseline or reference for the present climate. The projected climate-change signals for each time window are calculated as the difference between the future time windows (averages calculated over thirty years) and the reference period. For example, the rainfall change by 2050s is computed based on the difference in average rainfall between 2036 and 2065 and the reference period (1971-2000). This is because the conditions prevailing in any individual year will be affected by the natural climatic variability to predict rainfall reliably. In this analysis, reference was made to the validated model dataset for East Africa (Endris et al., 2013).

\subsubsection{Rainfall}

Under each of the three different scenarios and three future time periods, the projected changes in the annual rainfall component show relatively little change compared to the projected changes in the seasonal rainfall components (Figure 7). The short rains (OND) are projected to increase over most parts of the domain under all the three scenarios. In contrast, the long rains (MAM and JJAS) are projected to decrease over most of the region. The projected annual rainfall shows a tendency to increase over the western and south-eastern part of the region and decrease over northeast.

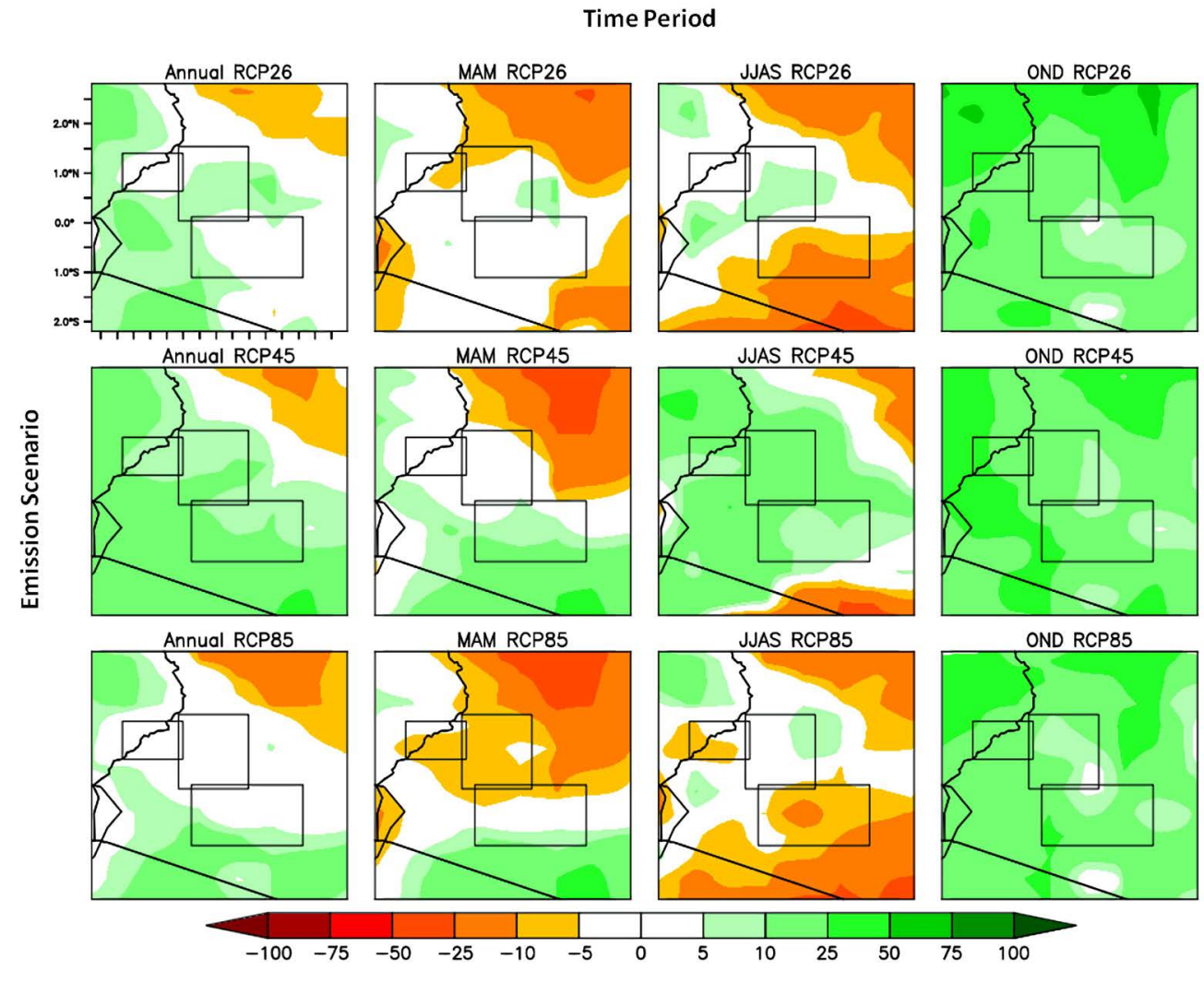


Time Period

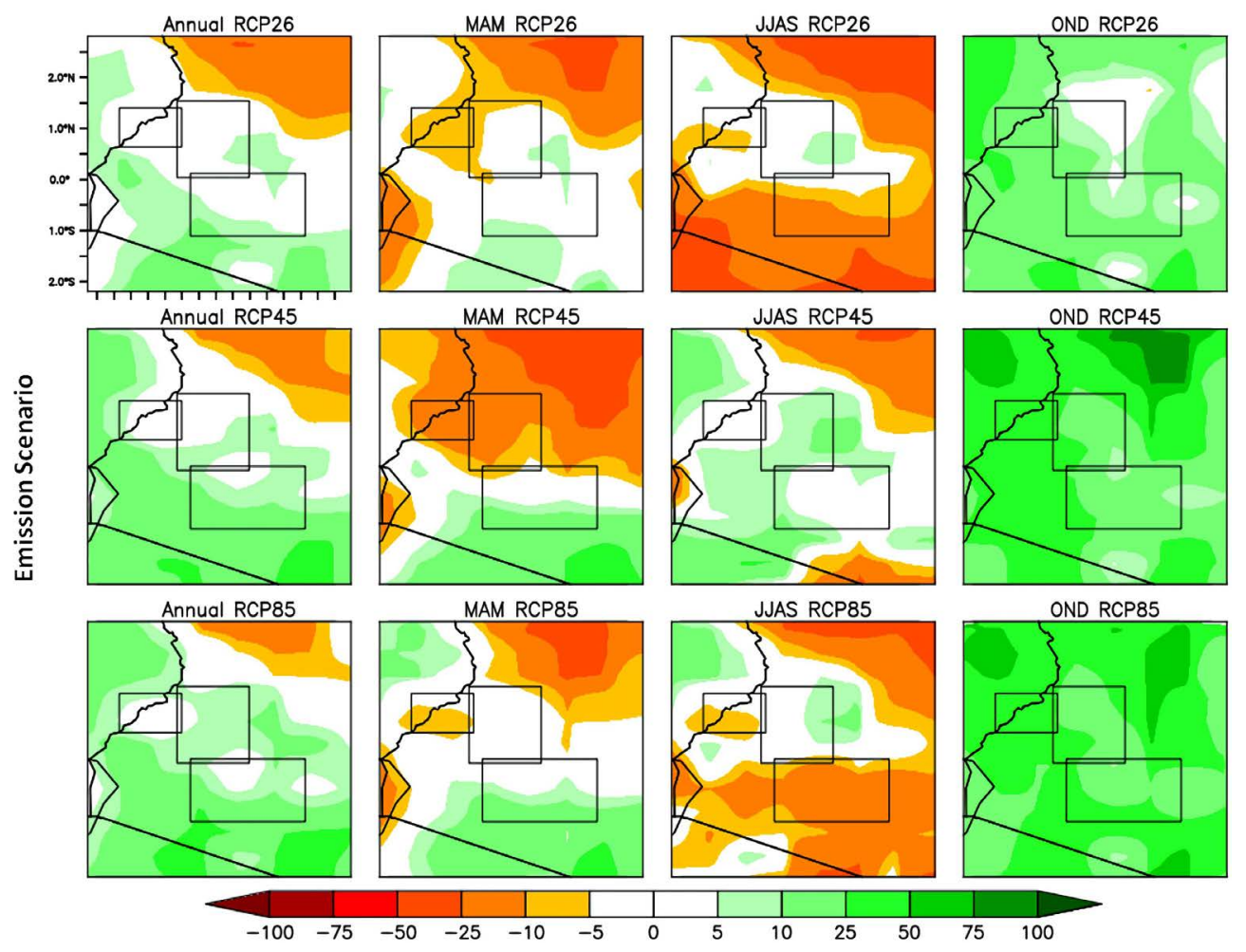

Figure 7. Projected rainfall changes by (top) 2030s, and (bottom) 2050's in different time periods and emission).

\subsubsection{Temperature}

The projected changes in maximum and minimum temperatures for the three scenarios (RCP2.6, RCP4.5 and RCP8.5) have been analysed for three future time slices of 2030s 2050s and 2070s. The results for 2070s are not presented. Figure 8 shows the projected changes in minimum temperature by 2030s and 2050s. The results show that almost all areas of the Kenya Water Towers will experience a warming trend. The expected warming extent is greatest during MAM and JJAS seasons and least during the short rains (OND). By the 2030s, annual minimum temperatures are anticipated to be $1.0^{\circ} \mathrm{C}$ to $1.5^{\circ} \mathrm{C}$ higher under the RCP2.6 and RCP4.5 scenarios but $1.5^{\circ} \mathrm{C}$ to $2.5^{\circ} \mathrm{C}$ higher under the RCP8.5 scenario over most parts of the region, with slightly less warming in the Mt. Elgon area. By 2050s, annual minimum temperatures are expected to be $1.5^{\circ} \mathrm{C}$ to $2.0^{\circ} \mathrm{C}$ higher under the RCP2.6; $2.5^{\circ} \mathrm{C}$ to $3.0^{\circ} \mathrm{C}$ higher under the RCP4.5; and $3.0^{\circ} \mathrm{C}$ to $3.5^{\circ} \mathrm{C}$ higher under the RCP8.5 scenarios over most parts of the domain, with slightly less warming expected in the Mt. Elgon area. The greatest potential warming will likely occur in the JJAS season. Results on Figures 9-11 show that the projected time series of annual maximum and minimum temperatures have similar variation tendencies as the emission pathway. For RCP2.6, the temperature continues to rise until 2050 and begins to cool slightly thereafter. For RCP8.5, the temperature continues to rise with the ongoing increase of radiative forcing. There are indications that the minimum temperature is warming 


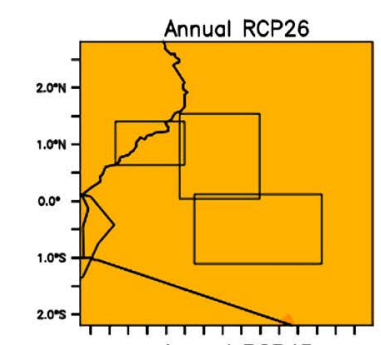

Annual RCP45

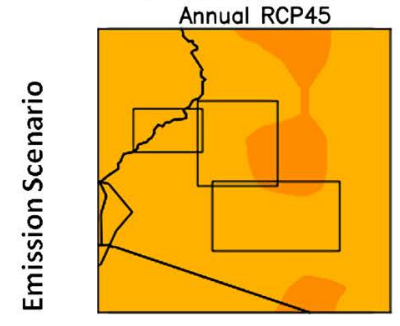

Annual RCP85
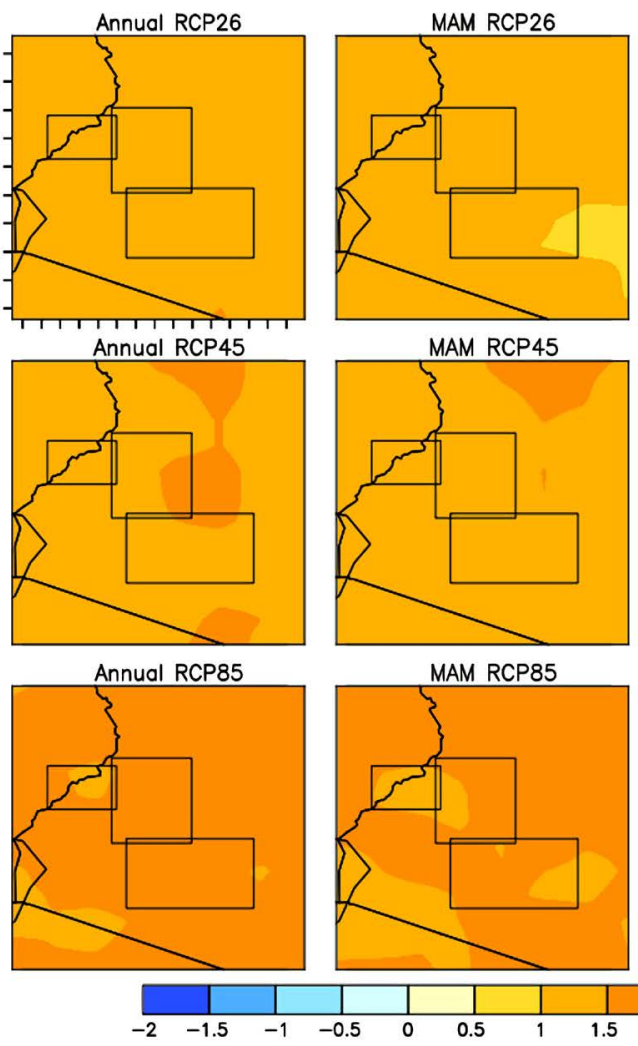

MAM RCP 45

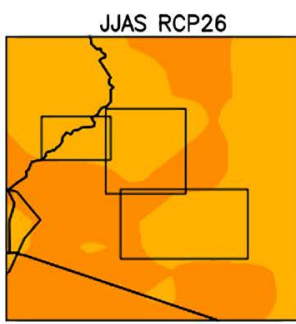

JJAS RCP45
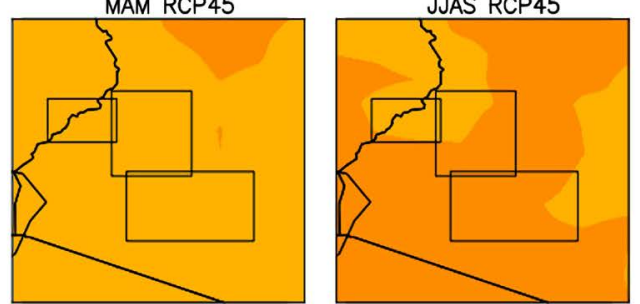

JJAS RCP85
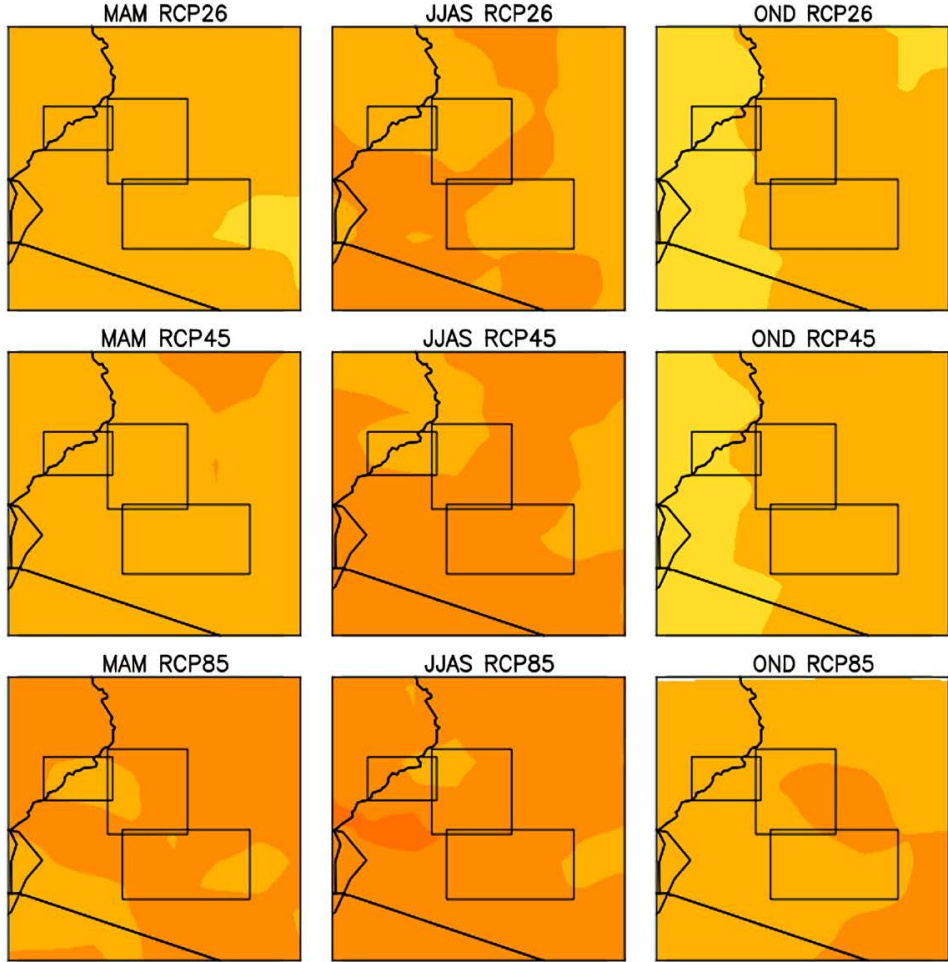

OND RCP45

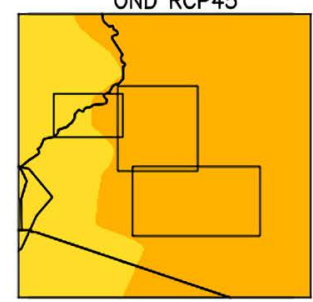

OND RCP85
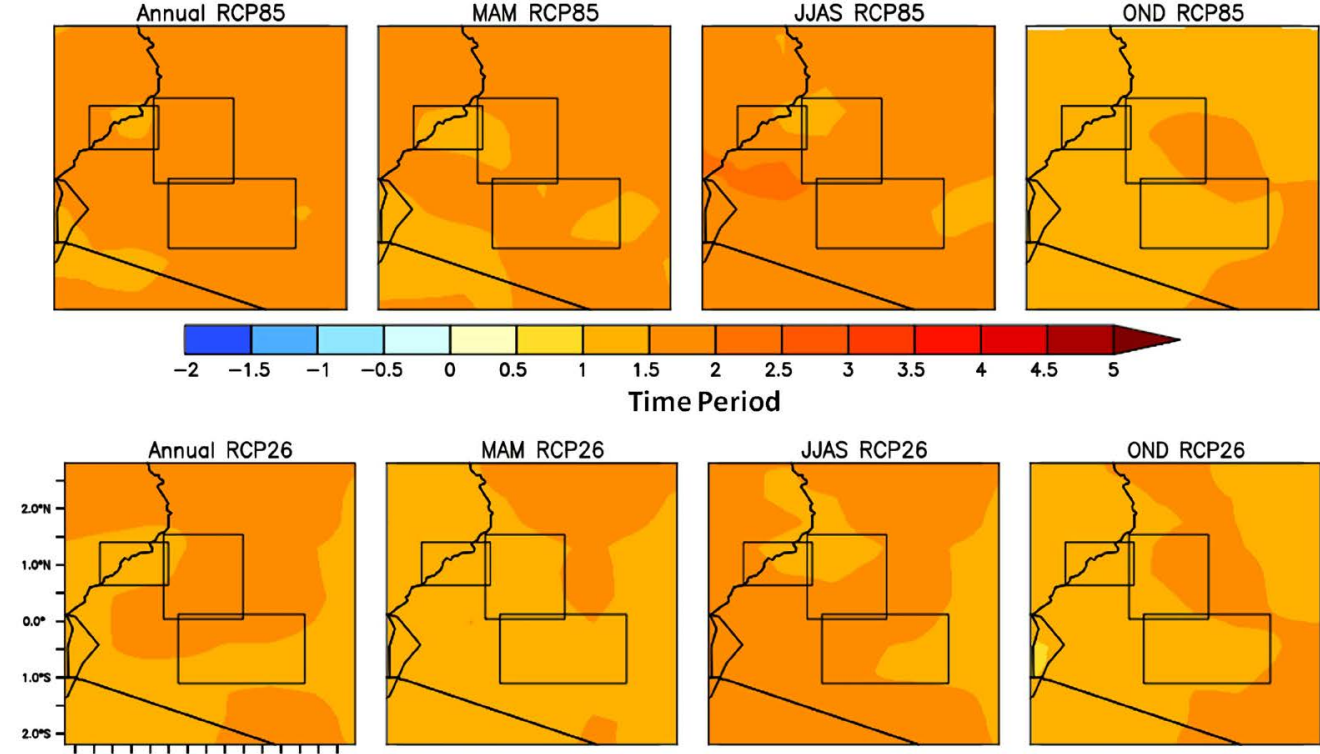

MAM RCP45
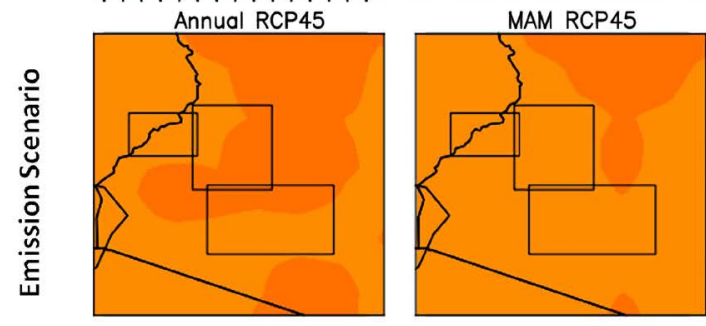

MAM RCP85
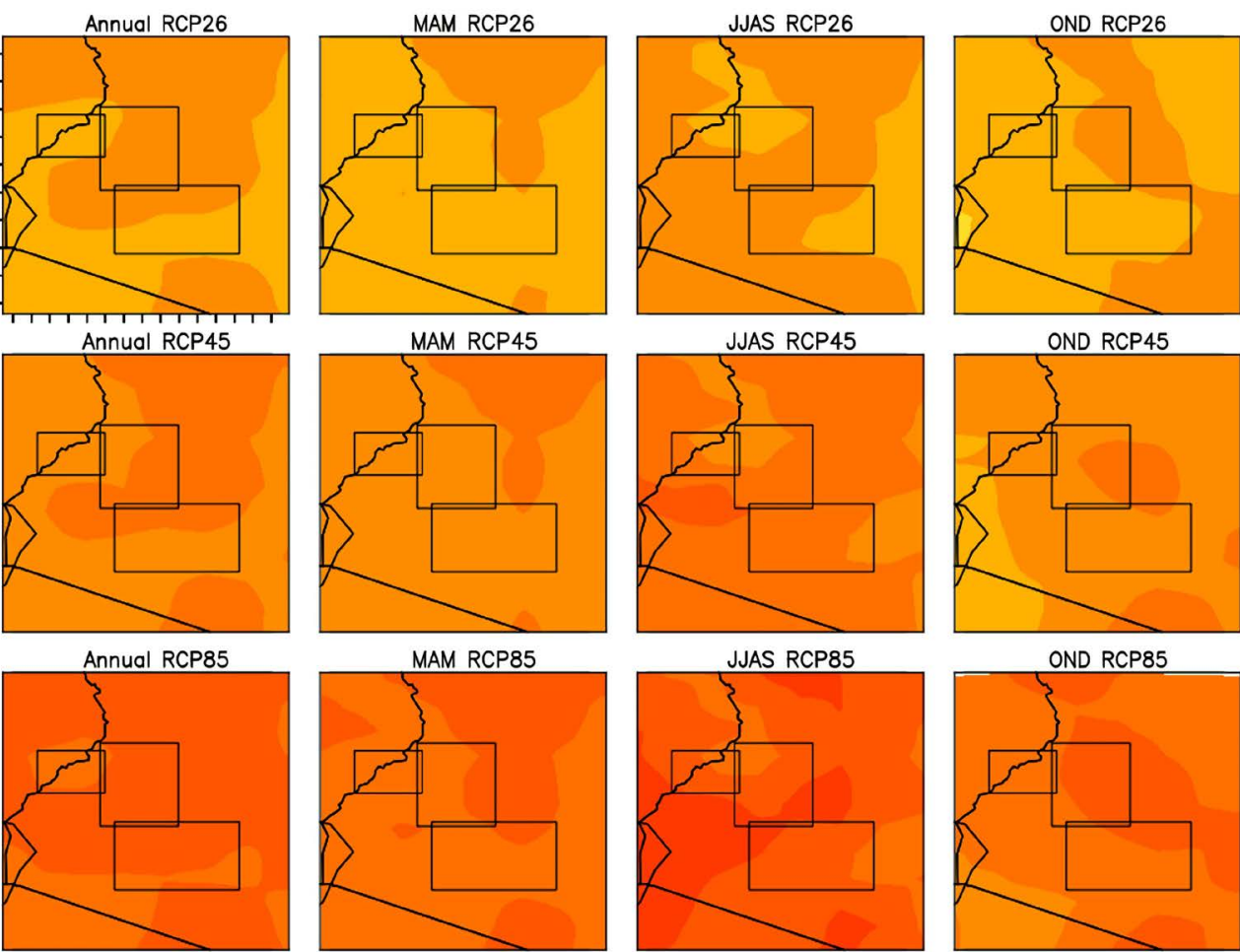

JJAS RCP45

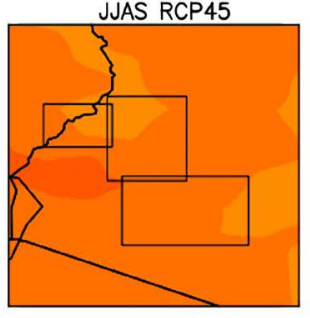

JJAS RCP85
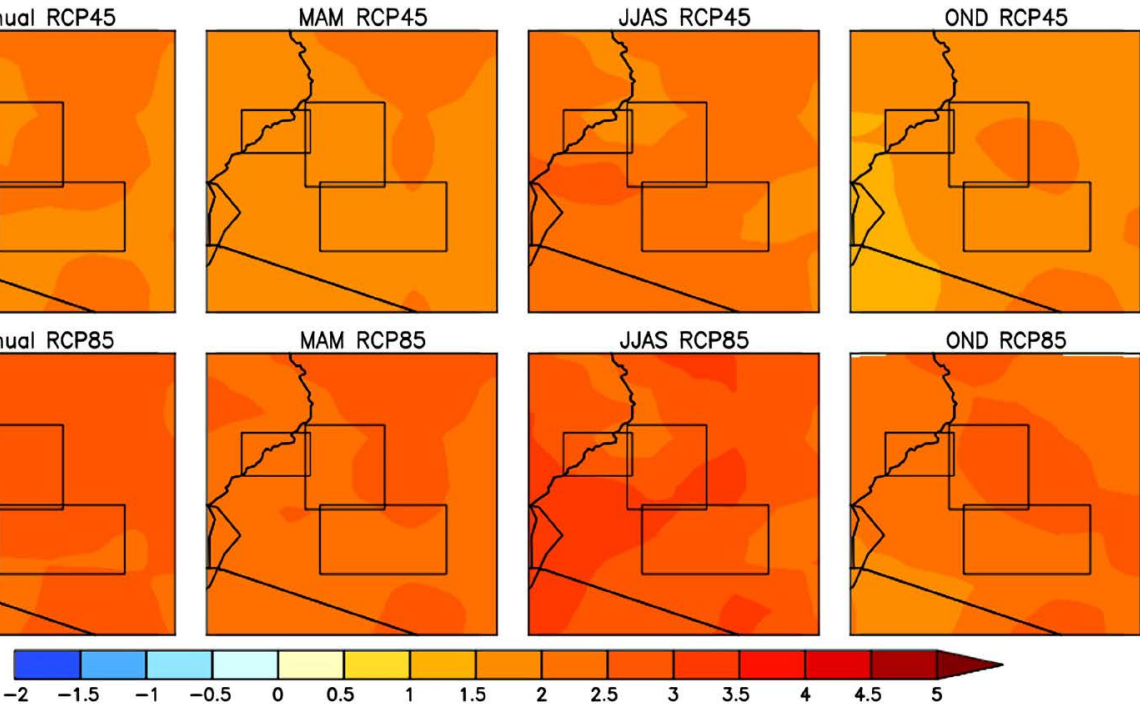

Figure 8. Projected minimum temperature changes by (top) 2030s, and (bottom) 2050's in different time periods and emission scenarios). 


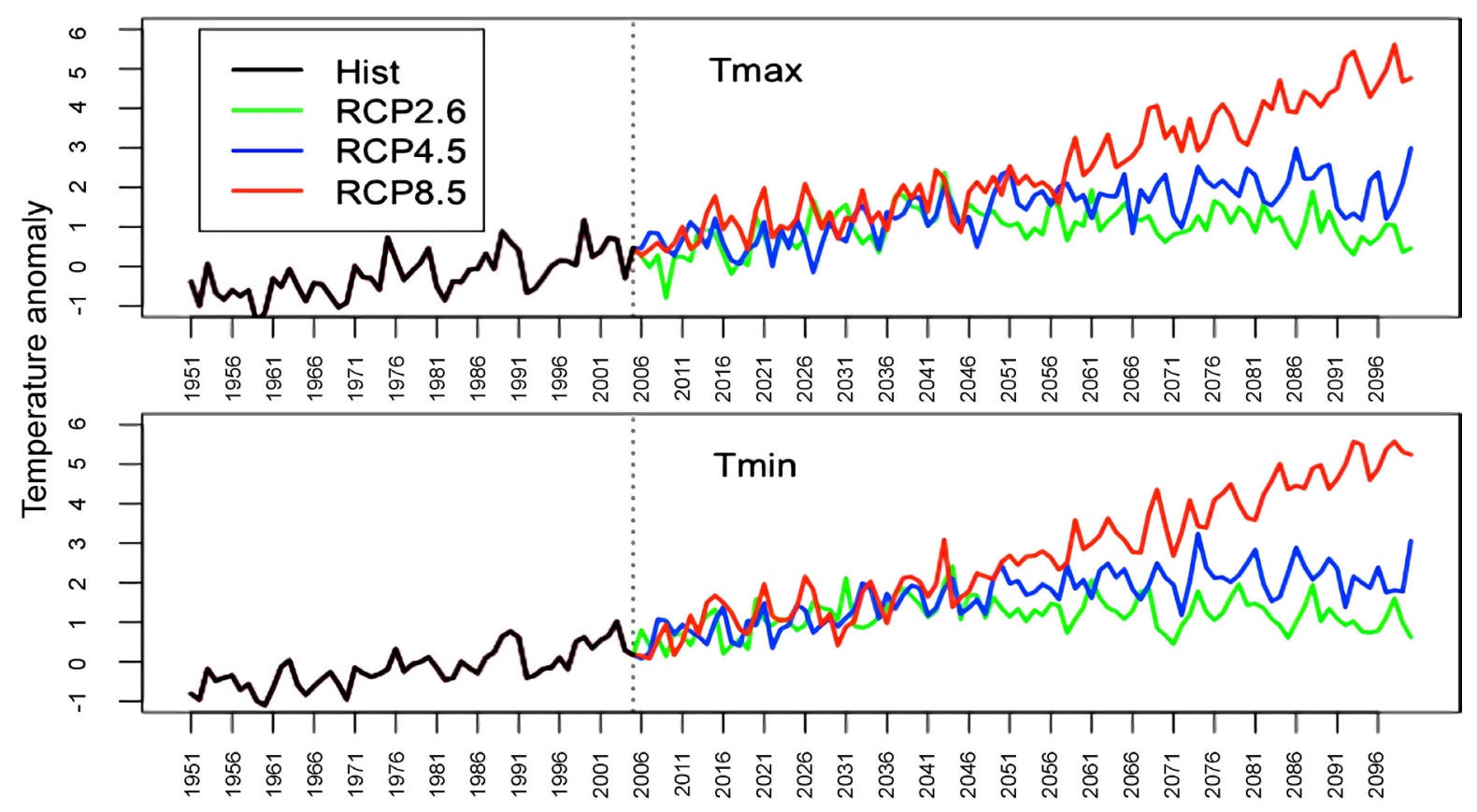

Figure 9. Time series of annual surface maximum (top) and minimum (bottom) temperature anomalies (units: ${ }^{\circ} \mathrm{C}$ ) over Mount Elgon water tower from 1950 to 2100 relative to 1970-2000.

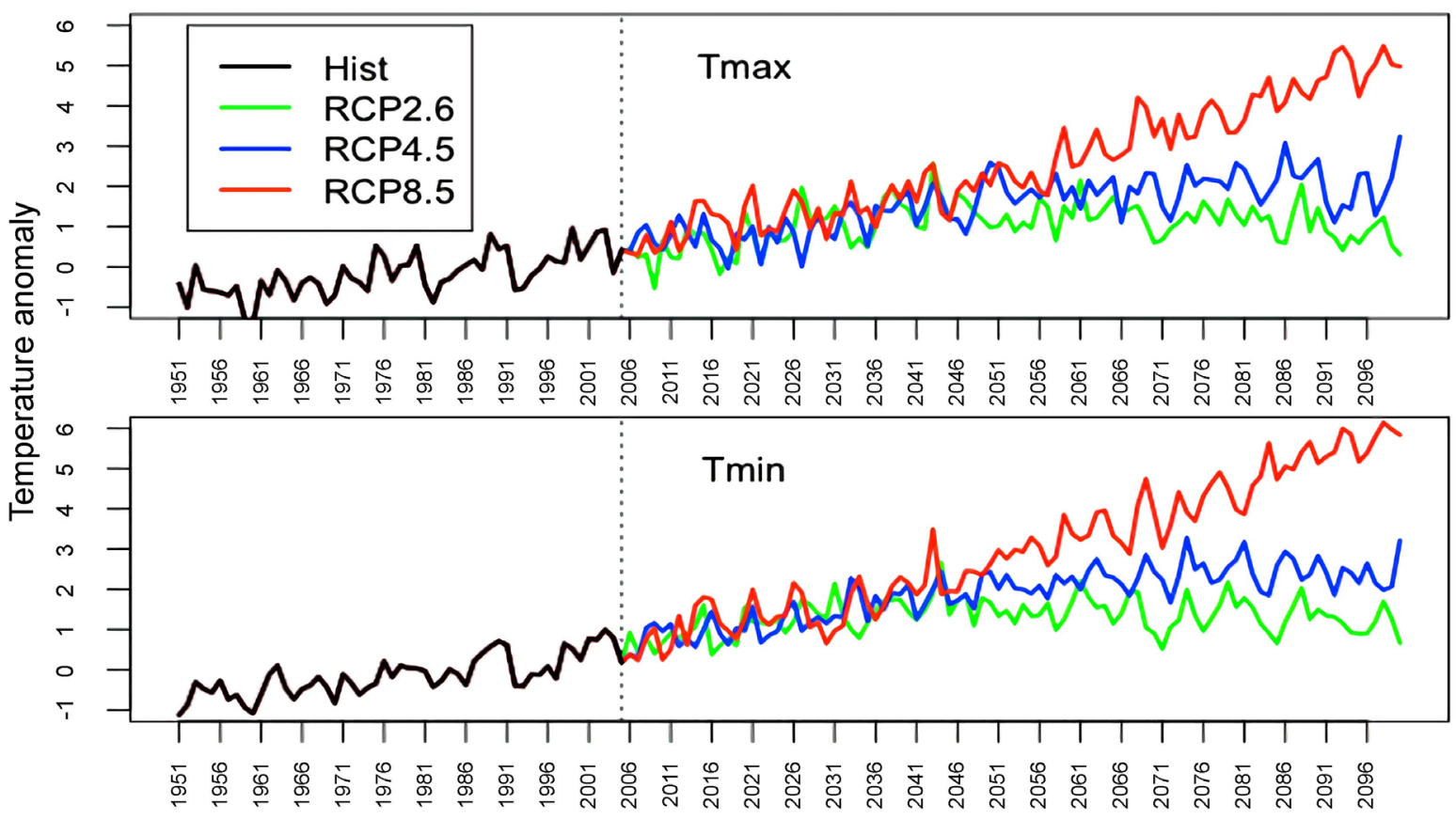

Figure 10. Time series of annual surface maximum (top) and minimum (bottom) temperature anomalies (units: ${ }^{\circ} \mathrm{C}$ ) over Cherangani water tower from 1950 to 2100 relative to $1970-2000$.

faster than the maximum temperature; this suggests that the gap between the maximum and minimum temperatures will likely be small in the future, compared to the present period. Moreover, the temperature increases over Cherangany Forest and Mau Forest Complex are higher than over Mt. Elgon. For example, by 2100 , the projected increase in the annual minimum temperatures will 


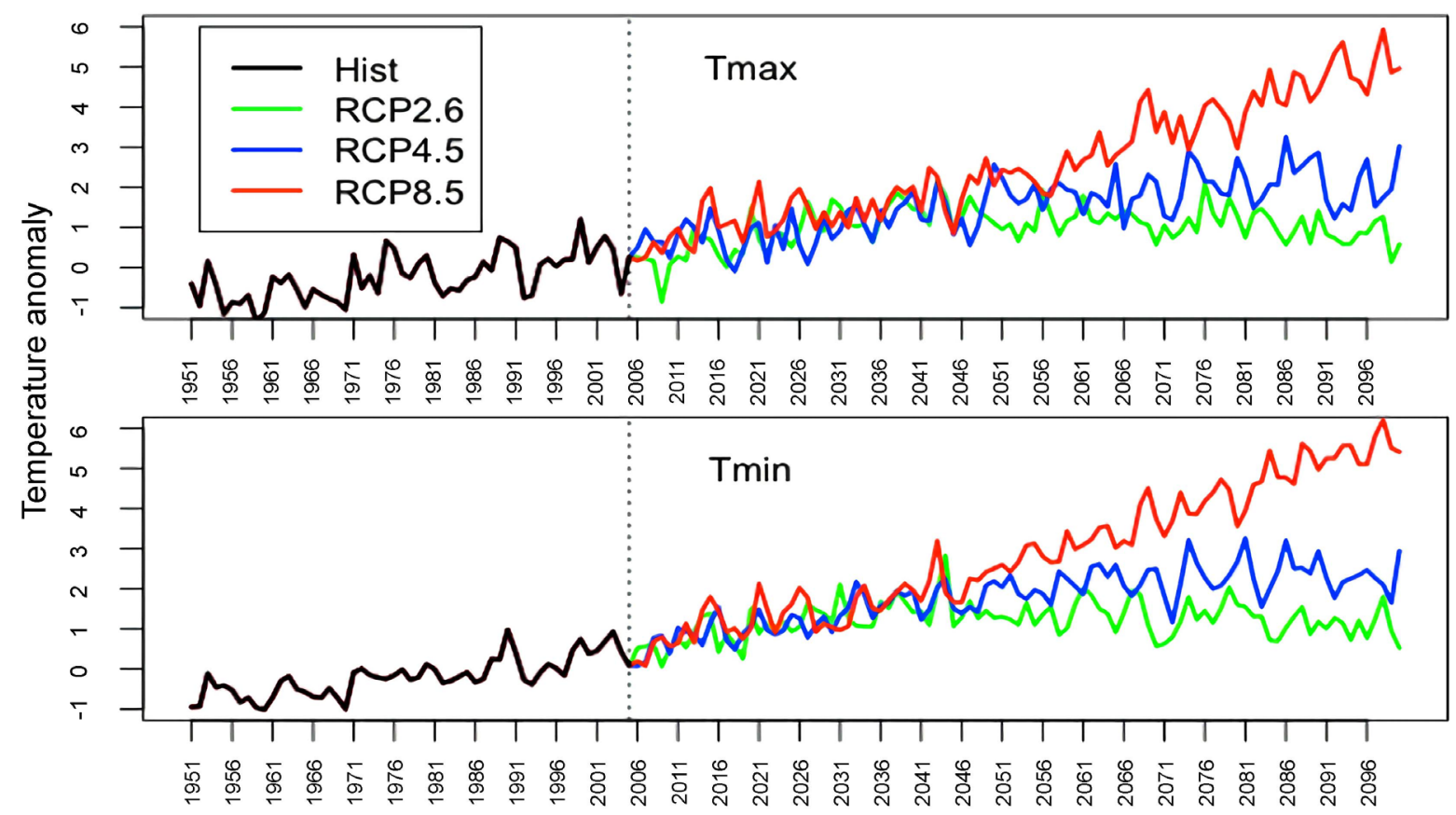

Figure 11. Time series of annual surface maximum (top) and minimum (bottom) temperature anomalies (units: ${ }^{\circ} \mathrm{C}$ ) over Mau Complex from 1950 to 2100 relative to 1970-2000.

likely be $6^{\circ} \mathrm{C}$ higher over Cherangany Forest and Mau Forest Complex under the RCP8.5 scenario relative to the base period, but the projected increase in the annual minimum temperature over Mt. Elgon will likely be $5.4^{\circ} \mathrm{C}$ to $5.7^{\circ} \mathrm{C}$.

\subsubsection{Standardized Precipitation Index (SPI)}

The results show that by the end of 2030s, the three Kenya Water Towers will experience more frequent and persistent droughts. This is also observed for the 2050s period (Figure 12). The spatial patterns of the frequency of twelve-month SPI by 2030s and 2050s, respectively, for wet and dry events for RCP2.6, RCP4.5, and RCP8.5 scenarios (Figure 13) indicate more frequent abnormally dry and wet events over Cherangany and Mau Complex in 2030s and 2050s, compared to other parts of the region. More frequent wet periods and events will occur over most of the region considering the RCP 8.5 emission scenario.

\subsubsection{Length of Crop Growing period}

For the communities that live around the three water towers, the results indicate that under the RCP 2.6 pathway, the overall signal is of a decline in length of the growing period (LGP) (figure not shown). However, under the RCP 4.5, the LGP has little change (5 days) in Mt. Elgon and Cherangany while over Mau, the LGP has a general increase of about 10 days. This pattern is contrasted in the RCP 8.5 scenario where a notable decline is evident in the Mau region. This shows that the seasonal variability is unique for the different pathways. The general pattern in changes in LGP observed in this assessment agrees with results obtained by Thornton et al. (2006) using different climate models. The projected increases in temperature and projected changes in rainfall patterns and amount (increases 

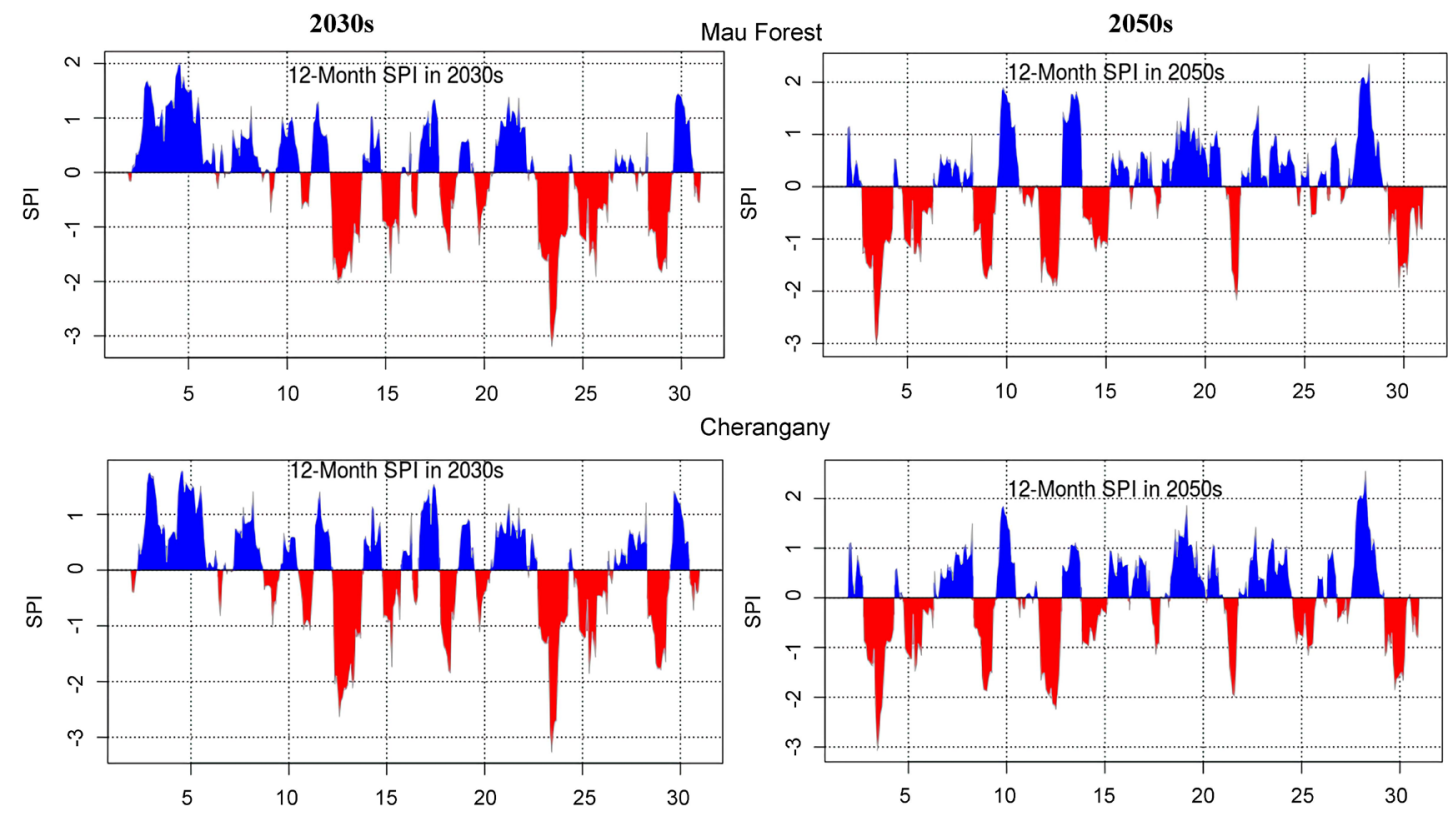

Mt. Elgon
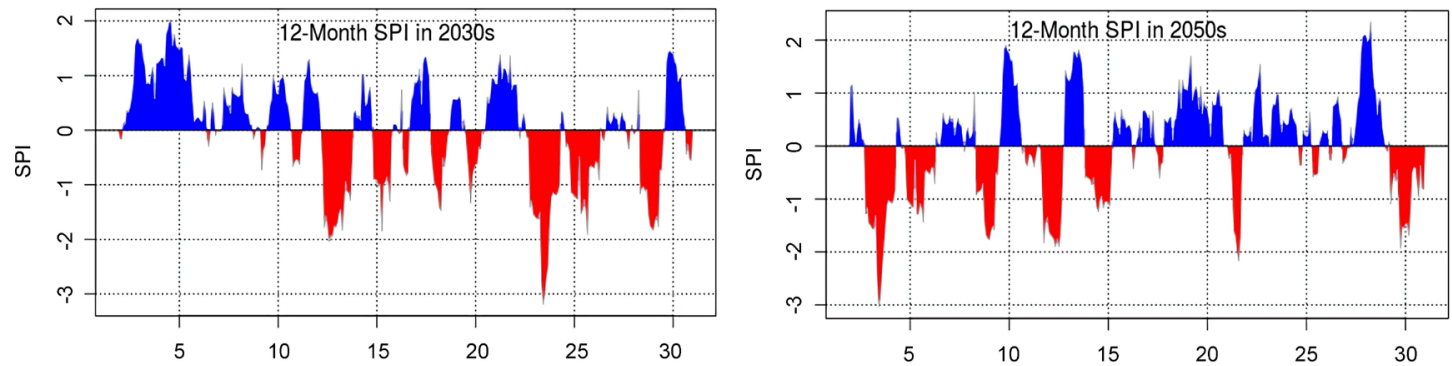

Figure 12. Twelve-month SPI in (a) 2030s and (b) 2050s over Mau Forest, Cherangany and Mt. Elgon.
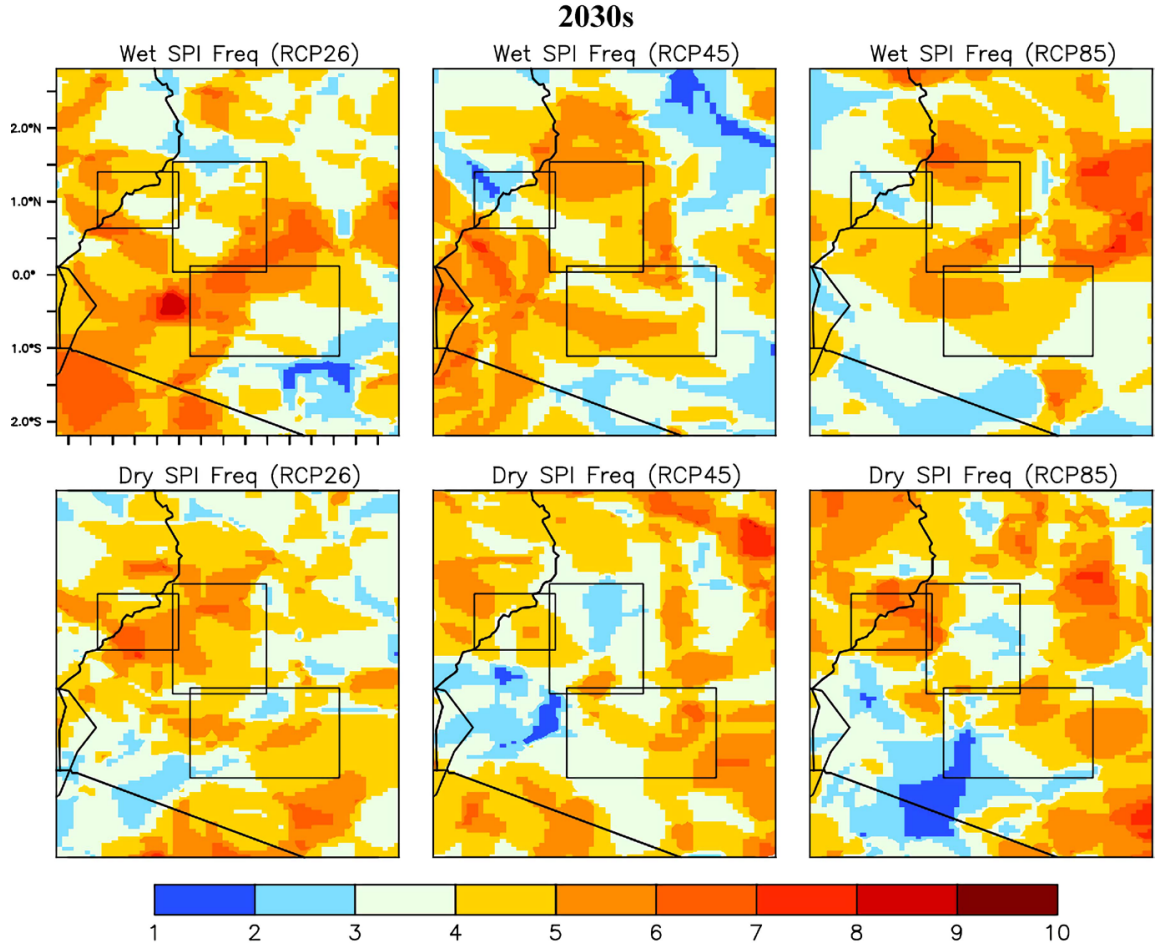
2050s

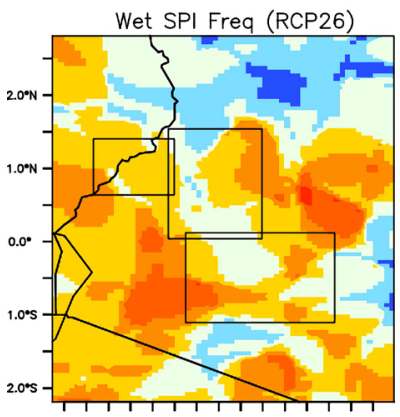

Wet SPI Freq (RCP45)

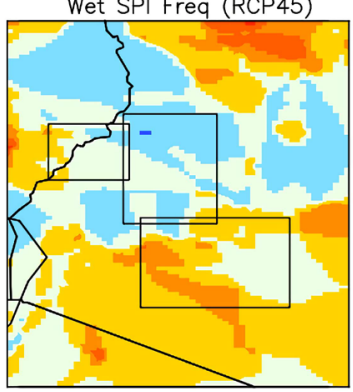

Wet SPI Freq (RCP85)

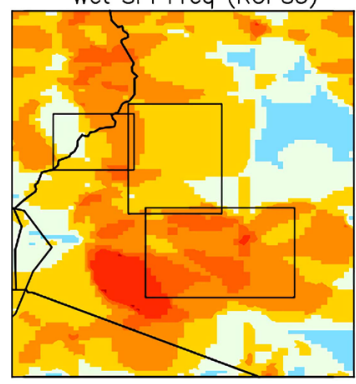

Dry SPI Freq (RCP26)

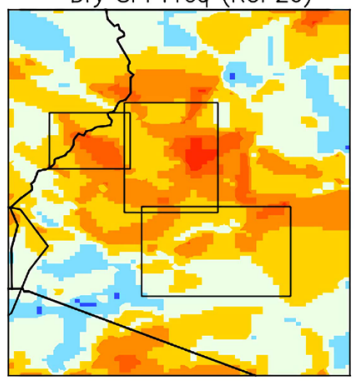

Dry SPI Freq (RCP45)

Dry SPI Freq (RCP85)
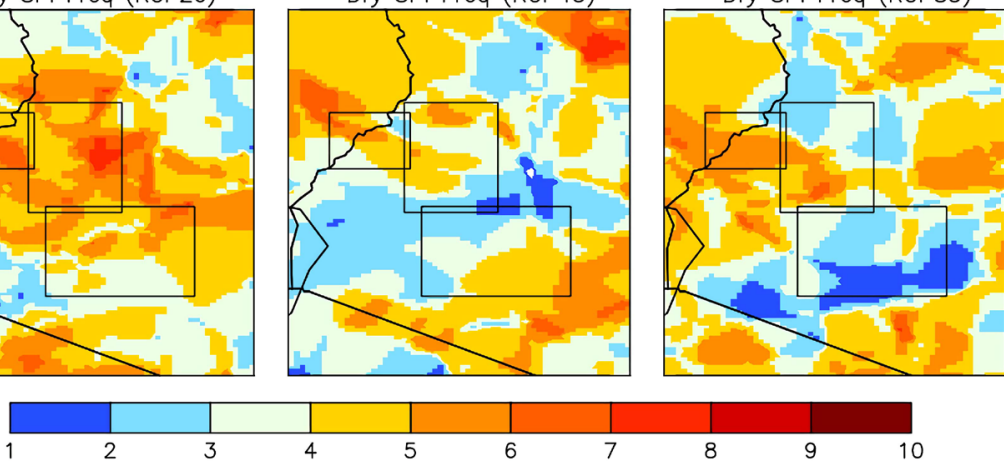

Figure 13. Spatial patterns of SPI frequency by 2030s and 2050s for wet and dry periods (Representative Concentration Pathway-RCP 2.6, 4.5, 8.5).

and decreases) combine to influence (increase and decrease) the length of growing periods. As outlined by Osbahr and Viner, 2006, the projected increases in rainfall in some areas may not be an advantage as this projected increase coincides with projected temperature increase leading to increased evapotranspiration rates which therefore cancels out the benefits of increased rainfall. Therefore, projected increases in LGP (RCP 4.5. and 8.5) might translate to very minimal positive impacts on crop productivity.

\subsection{Impact on Water Resources}

Understanding how climate change will impact water flows is one of the most pressing issues for Kenya. Success of the Government of Kenya development agenda will be dependent, in part, on adequate water resources to drive irrigated agriculture to ensure food security. The water sector plays a fundamental role in the economy of the country, as it is a key component of other sectors including, agriculture, energy, health and industry. The water sector in Kenya is increasingly becoming vulnerable due factors ranging from population increase, land use changes, infrastructure deterioration, and climate change.

We quantified the changes in mean annual stream flows for predicted rainfall patterns and RCP's $(2.5,4.5$. and 8.5) for NF, MF and FF periods. Figure 14 shows the projected changes in long-term mean flow for the various rivers under different climate change scenarios and time periods. Generally, most rivers show a decreasing trend in water availability in predicted future climates, with a few 


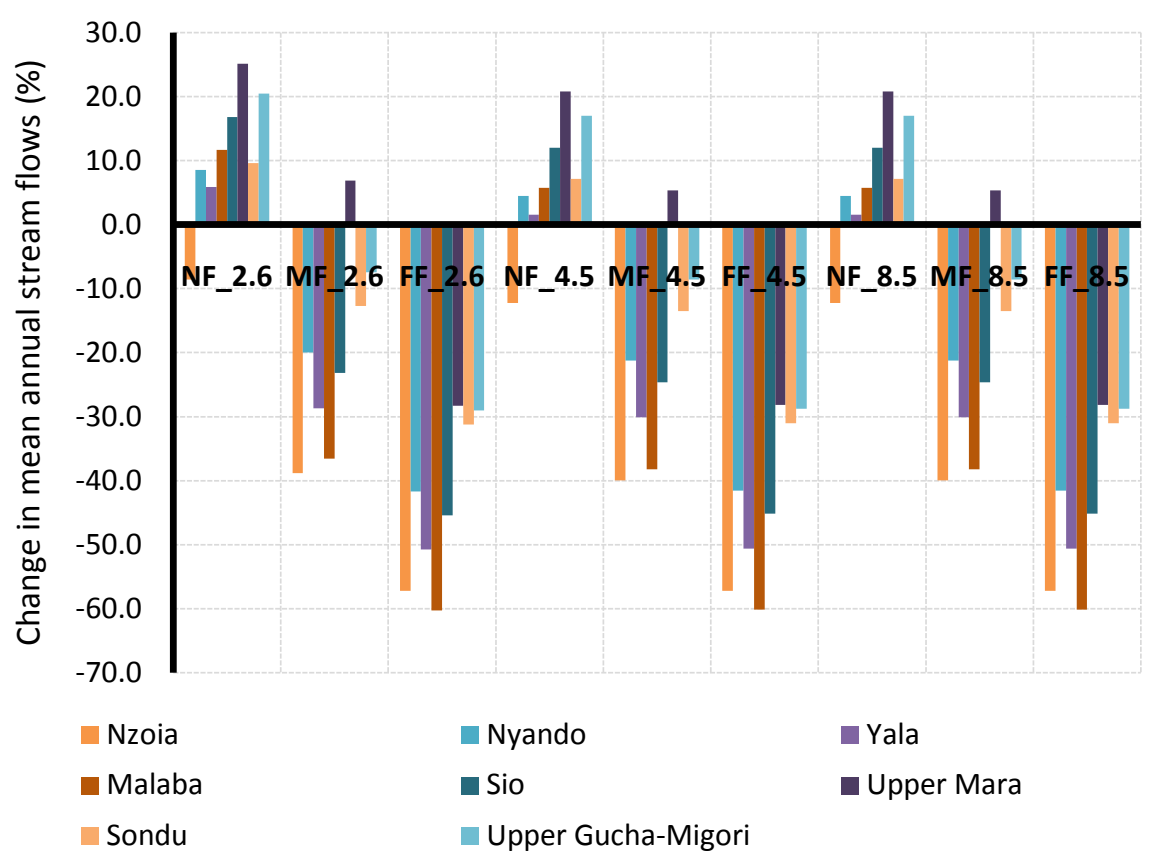

Figure 14. Percent changes in streamflow due to projected climate changes in selected rivers for Near Future (NF), Middle Future (MF) and Far Future (FF) periods for the three Representative Concentration Pathway RCP's (2.6., 4.5 and 8.5).

exceptions. Upper Mara, Upper Gucha-Migori, and Upper Ewaso Ngiro South Rivers give mixed signals with the both Near Future and Mid Future scenarios showing increasing water availability trends, while all Far Future scenarios show a decreasing trend. Increasing trends in catchment water yield have also been observed by Rwigi (2014) in modelling studies of the Sondu catchment. The predicted increase in the OND period is likely to result in increased flood frequency and severity. However, the predicted temperature increases will result in increased drought frequency and severity, and therefore water resources will be negatively impacted.

Predicted higher rainfalls will result in increased incidences of flash flooding especially in areas with steep slopes. Increased flooding frequency in recent years in Narok and Nyando not only negatively impacts infrastructure but also results in immediate water deficits despite the increased rainfalls. The positive impacts of predicted increases in precipitation are curtailed by increases in temperature causing higher evaporation rates. These higher evaporation rates translate to depleted soil moisture levels and subsequently aquifer water storage is depleted, and low flows are also negatively impacted. Although not explicitly evaluated in this assessment, the predicted changes in climate and associated hydrological fluxes have direct consequences on water quality. Changes in precipitation (increase and decrease) impact surface runoff and sediment loading which pose challenges of increased costs for water treatment, and this cascades into higher risks for fresh water supplies and public health. However, it is important to state there are high uncertainties in the scenarios as these projections are impacted by future resource use and management decisions. 
Impact on the Seasonal Flow Distribution, Consumptive Use, Availability and Deficit

Discharge from rivers with headwaters originating in Mt. Elgon Water Tower exhibits two peaks, following the two rainy seasons, and the simulation results, based on climate-change scenario data, indicate that as the short rains surge, the peak flows also increase. In the case of Malaba River, the flow in the short-rains season becomes equal to that of the long-rains season. There is also a trend of lower-than-baseline flows in the July-September season and higher-than-baseline flows in the January-March season. The Far Future RCP8.5 scenario shows below-baseline flows in all the months except January and February. As observed for the Mt Elgon Water Towers, streams emanating from the Cherangany Water Tower also indicate significant changes in the monthly mean flows. Except for RCP8.5, the scenarios indicate that the mean flows during the September-March time period will be higher than the current conditions (baseline), whereas AprilAugust flows will be lower than the baseline. In the case of Cherangany, peak flows are in the month of May, as is the baseline. The trend in the other two Water Towers is replicated in Mau, but the reduction or increase of the flows is less significant in this Water Tower-especially for Ewaso Ngiro South River. The exceptions are the RCP8.5 scenario for the case of Gucha-Migori and Mid Future RCP 2.6 scenario in the case of Upper Ewaso Ngiro South, which show up to a 50 percent reduction in mean monthly flows in the May-September season.

The total consumptive water demand in Western Kenya is $26 \mathrm{~m}^{3} \cdot \mathrm{s}^{-1}$ with the main catchments being Nyando $\left(11 \mathrm{~m}^{3} \cdot \mathrm{s}^{-1}\right)$, Nzoia $\left(8 \mathrm{~m}^{3} \cdot \mathrm{s}^{-1}\right)$, and Yala $\left(5 \mathrm{~m}^{3} \cdot \mathrm{s}^{-1}\right)$. As the water availability decreases, especially in the Far Future for all three scenarios, the water supply deficit (shortage) also increases. Nyando basin has a maximum of 46 percent deficit in the Far Future RCP2.6, 4.5, and 8.5. As outlined in the National Water Master Plan (2030), water demand will increase in all catchment areas in Kenya over the next few decades and while some areas are expected to have increased rainfall, the water balance is generally expected to be tight in all areas with higher water stress levels. Additionally, with an estimated 92,000 ha of possible irrigated area in the Rift valley catchment (KWMP-2030), putting this much land under irrigation will further increase the water demand deficit. Added to this demand is the impact of ecosystem degradation, including deforestation, on the Water Towers water storage capacities. The observed changes in water availability deficit and water demand deficit are important to water resource managers and policy makers to inform long-term planning. These results also provide insights into how changes in water demand deficits will likely complicate future water management in an environment of increasing population.

\subsection{Overall Vulnerability Index}

Climate Vulnerability Index (CVI) was estimated for the three ecosystems in terms of exposure, sensitivity and adaptive capacity (Figure 14) for the base period. Vulnerability Index projections were also quantified for mid-future and far-future, under RCP 4.5 and RCP 8.5. As outlined by Swanston \& Janowiak (2012), nega- 
tive potential impacts and low adaptive capacity indicate high vulnerability and vice versa. The ecosystems exhibit low to moderate vulnerability (Figure 15), with High to Very High vulnerability levels exhibited in the landscapes outside the Water Towers. The least vulnerable forest blocks in Cherangany are Chemurokoi, Cheboit and Kiptaberr while the most vulnerable forest blocks are Kamatira and Lelan the Northernmost blocks. 13\% of the area of Kamatira is highly vulnerable while $2 \%$ of Lelan is highly vulnerable. In the Mau Water Tower $30 \%, 63 \%$ and $6 \%$ of the total area are in the Low, Moderate and High categories respectively. The most vulnerable blocks of Mau are Maasai Mau followed by Transmara and Eburu forest blocks. All the three forest blocks are surrounded by areas that are highly vulnerable and few spots of areas that are very highly vulnerable. Of the three Water Towers, Mt. Elgon is the least vulnerable with $57 \%$ under the Low category.

Due to the projected stress from future climate scenarios, the vulnerability of the Water Towers will increase in the future. The variations in magnitude and direction of change imply that the vulnerability will be varied spatially across the

\section{Current (2015)}

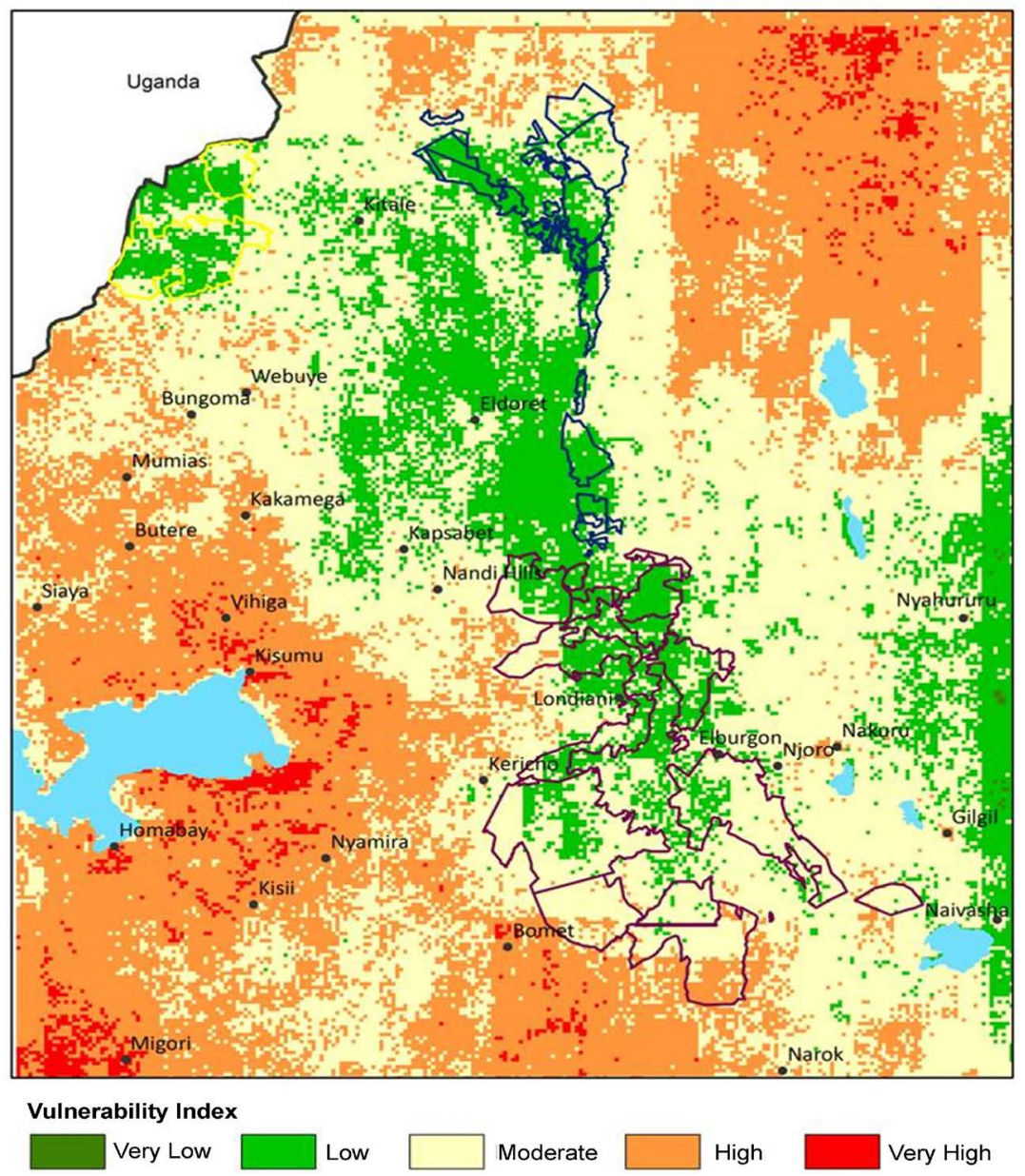

Figure 15. Current (2015) Climate Change Vulnerability Index map of the Water Tower Ecosystems. 
Water Towers. Results from this assessment suggest that forests in the Water Towers are likely to experience significant stress because of their climate exposure, sensitivity to climate-related stressors, and adaptive capacity. This may result in a change from forest to non-forest. Climate conditions may be suitable for other species, e.g. invasive species to thrive. As there is limited information, current research being undertaken by the Kenya Forestry Research Institute (KEFRI) analysing the spatial and temporal trends in the spread of invasive species in the Water Tower ecosystems can help to inform the ecological vulnerability. Generally, as outlined by Ogden and Innes, (2007), species-rich communities exhibit greater resilience to extreme environmental conditions than less diverse communities. The combined impacts of forest diversity alteration due to climate change and human impacts (deforestation) will therefore increase the vulnerability of the Water Tower ecosystems as reflected in Figure 16. The level of vulnerability
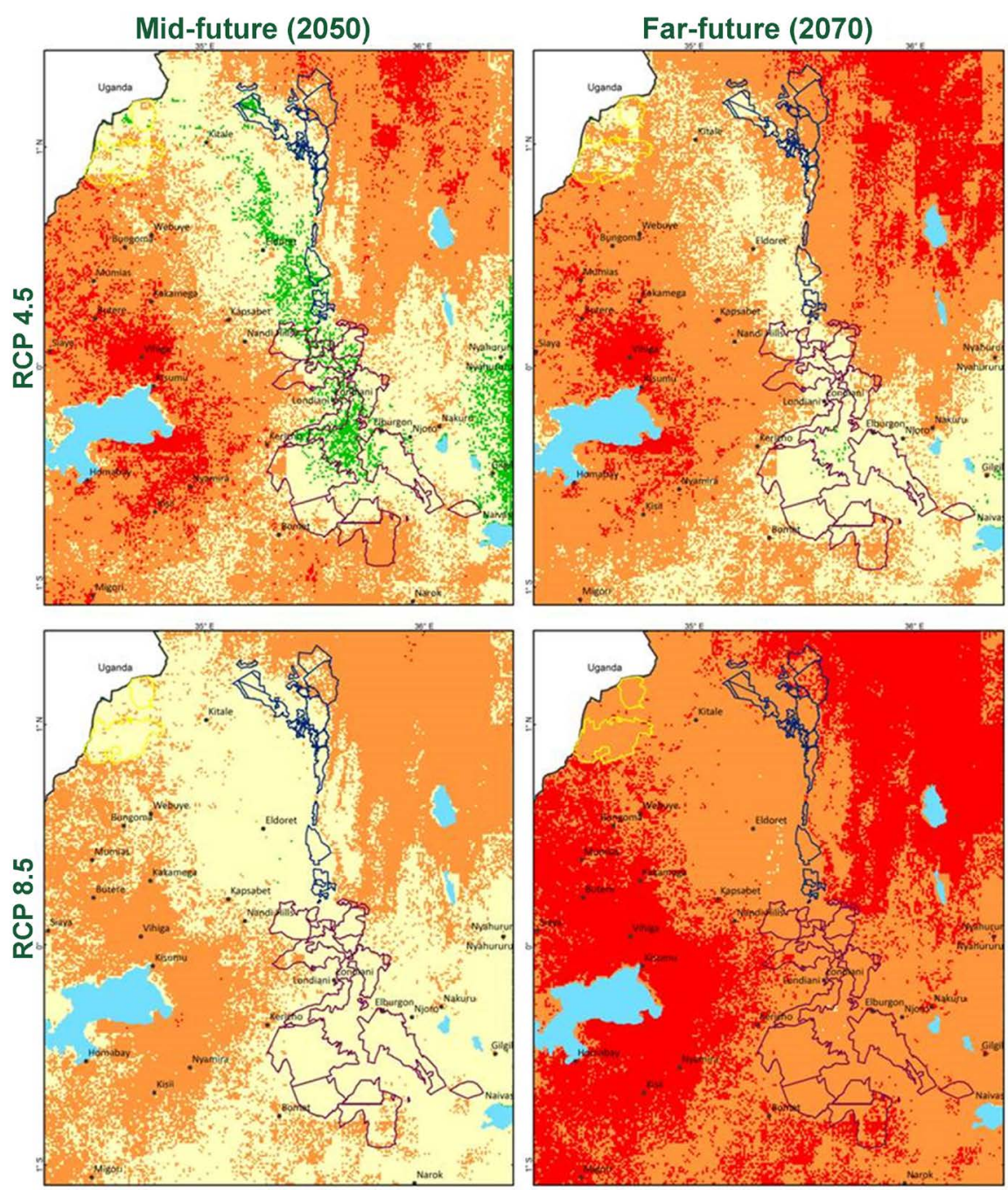

Vulnerability Index

Very Low

Low Moderate High

Very High

Figure 16. Climate change vulnerability in Future periods for Representative Concentration Pathway (RCP) 4.5 and 8.5. 
and the rate of increase of vulnerability also vary from one Water Tower to another. The exposure indicators for the future scenarios used the current values as the baseline; therefore, the measure of exposure is relative to the current climate conditions.

In the current period (2015), approximately 40 percent of the total area of the Water Towers was classified as low vulnerability. In both RCP 4.5 and 8.5 scenarios, the area under low vulnerability shrinks significantly in the Mid Future (2050s) and is almost non-existent in the Far Future (2070s). In RCP 4.5, the area under moderate vulnerability increases in the Far Future, while the area under high vulnerability increases in the Mid Future and then decreases in the 2070s. In RCP 8.5, the area under high vulnerability shows a significant increase (up to 93 percent) in the 2070s. Vulnerability in the low-emission scenario (RCP 2.6) during the years 2050s and 2070s shows a reversed trend lower than the baseline (current vulnerability). This is mainly because temperatures are projected to increase minimally $\left(1^{\circ} \mathrm{C}\right.$ to $\left.1.5^{\circ} \mathrm{C}\right)$ while rainfall increases considerably (up to $10 \mathrm{~mm}$ ) under RCP 2.6. This represents an ideal situation, if all international frameworks for climate change mitigation are adopted and implemented. However, this is unlikely, since even with the implementation of the various international frameworks meant to reduce carbon emissions, it may take time for the effects to manifest in the climate and biophysical environment.

\section{Discussion and Recommendations}

The CCVA reported here was undertaken to support informed planning, design and implementation of climate-change adaptation and resilience activities in the water tower ecosystems. This can be achieved through spatial planning, including anthropogenic activities, for ecosystem-based climate change responses that benefit both communities and biodiversity. The vulnerability indices can be used to inform priority actions and the allocation of budgets to reduce vulnerability most effectively. The Government of Kenya (GoK) recently launched the Green Economy Strategy and Implementation Plan (GESIP) 2016-2030, and the National Climate Change Action Plan (NCCAP) 2018-2022. These strategies seek to enhance resilience and adaptation in various sectors. The CCVA provides characterizations of current and future climatic, environmental, and socioeconomic conditions for the water towers ecosystems, therefore detailing a baseline for choosing and implementing mitigation and adaptation strategies.

Based on literature, field surveys, and results of this study, it was observed that although the socioeconomic roles and threats to the three water towers are more or less similar, each ecosystem showed unique and varying signals in terms of climate and non-climate stressors, sensitivity, and adaptive capacity across time and space. This suggests that each water tower requires unique interventions that target the forest resources, specific value chains-for instance, maize and tea crops, livestock and, water-to build resilience among the communities and to protect and enhance the productivity of the water tower ecosystems. If the live- 
lihoods of communities are affected, residents will resort to exploiting forest resources. It is therefore true that if you take care of the people in the forests, the people will take care of the forests for future sustainability of the ecosystem.

The impacts of human activities such as grazing and clearing land for agriculture will be magnified by climate change, as increasing temperatures and more irregular rainfall exacerbate problems. These adverse impacts can be mitigated by land restoration activities, such as planting trees and other vegetation, and water management strategies that seek to hold water in place. Sustainable land stewardship will include activities that build resilience in landscapes to an uncertain future. This is also the strategy best able to support the human population in the long run. Poor land management will mean the human community will be more adversely affected by flooding, drought, crop failures, and wildfires. Restoration activities such as tree planting can also benefit people by providing employment and the ecosystem services of holding water on the land, ameliorating high temperatures, and eventually producing sustainable wood products.

\subsection{Adaptive Capacity}

The adaptive capacity of the water tower ecosystems is a function of the inherent adaptive capacity of trees and forest ecosystems, and it is susceptible to socio-economic factors. A review by Bonal et al., (2016) shows great diversity in tropical forests adaptive capacity. The forest ecosystems in Kenya have faced serious challenges from stressors that mainly include illegal logging, agricultural land and settlement expansion and livestock grazing. A survey by Seswa (2012), in Kakamega forest showed that in an area of 22 hectares, a total of 35 species were targeted for logging. Large sections of these forests are in different stages of ecological succession which has direct impacts on their adaptive capacities. These drivers have direct negative impacts on ecological biodiversity in the forest ecosystems and therefore reduce the adaptive capacity. Therefore, protected areas such as the forest in Mt Elgon National park have high adaptive capacities.

Although not quantitatively evaluated in this assessment, generally, water deficits (due to declining rainfall amounts) will lead to a decline in forest cover, biomass, and tree species that are more tolerant to drought but slower-growing will thrive. This is evident from a global review by Pfeifer et al. (2018). A recent study (Tarus, 2017) in Arabuko Sokoke forest, shows that tree biomass is significantly related to rainfall, and temperature (maximum and minimum) with tree species distribution strongly influenced by annual trends, seasonality and extremities of rainfall and temperature patterns. This change in forest species composition increases vulnerability and reduces the adaptive capacity of the forest ecosystems. Key ecosystem services such as carbon sequestration will be severely impacted.

Pfeifer et al. (2018), also observed that higher minimum temperatures were also linked to increased canopy leaf area and canopy closure, suggesting a potentially positive response of forest functioning to global warming (Nemani et al. 
2003). However, they also emphasize that such analyses of climate change impacts need to balance structural changes in tropical forests in response to warming with the trees demand for water, since the majority of trees operate within relatively limited hydraulic safety margins (Choat et al., 2012).

As outlined by Locatelli et al. 2010, forest ecosystems require a combination of measures that target buffering forests from disturbances through increasing their resistance and resilience; and measures that support ecosystem shift towards a new desired state, in order to improve the adaptive capacity of forest ecosystems. The livelihoods of the communities surrounding the water towers are strongly linked to forest resources and water availability for agriculture, including crop and livestock production. Climate change and variability-including extremes and other intra-seasonal descriptors, such as onset, dry spells, cessation, and length of the growing season-are key drivers of productivity in the water tower due to a total reliance on rain-fed agriculture.

Farmers reported increasing temperatures, declining rainfall, and shortening growing seasons due to last onset and early withdrawal of rains in the area. Major crops-including maize, Irish potatoes, and, recently, beans-have been introduced in the area as the water levels in the lowlands now favor the crops. In addition, farmers rely on livestock, beekeeping, and forest resources, such as wood, charcoal, and plant medicine.

The communities are highly vulnerable to the effects of climate variability and change, due to low adaptive capacity (low resilience), and low social capital. It was reported (through the key informant interviews) that population pressure on the forest resources is quite high and expected to increase over time. In addition, the high level of livestock grazing affects the regeneration of the forest.

Programs that support appropriate coping and adaptation mechanisms need to be introduced to help reduce the pressure on the forest resources. Illegal charcoal burning, illegal tree logging, and wood trade are some of the illicit activities prevalent in the water tower ecosystems. Charcoal production is a potential source of forest fires, which account for a large proportion of forest loss and degradation. Education and awareness campaigns on agroforestry, renewable energy (especially biomass), drought-tolerant and early maturing crop (maize) varieties, soil and water management, and conservation practices need to be introduced in the region to strengthen the resilience of communities and cushion them against climate change effects. Farmers should also use weather advisories for decision making and early action to minimize climate-related losses.

Climate risks associated with weather variability, including extremes and changes in intra-seasonal characteristics, have been experienced in the water towers. This manifests in frequent drought occurrences, late onset of rainfall, dry spells, early rainfall withdrawal, and increasing temperatures. The consequences include low agricultural yields and crop failure, pests, diseases, forest degradation and forest fires, among others. Farmers have started adapting to the changing climatic conditions to minimize the risks of crop and animal losses. The 
adaptation techniques currently implemented include early planting, crop diversification, intercropping, improved crop varieties, beekeeping, agroforestry and tree planting. Forest managers have turned to adaptation techniques such as the earlier planting of seedlings to ensure survival and reduce the cost of replanting in the tree plantation areas.

The county governments and national government should focus on policies that invest in water for irrigation, resilient crops research, and promoting and subsidizing hybrid seed varieties. In the areas where the forest ecosystem suffers from the loss of some tree species, focus on re-establishment of indigenous tree species that have borne the brunt of loggers

\subsection{Rehabilitation of the Water Tower Forest Ecosystems}

To enhance resilience and adaptation, there is a further need to accelerate and promote activities aimed at rehabilitating degraded sections of the water towers ecosystems. The GoK has pledged to restore 5.1 million hectares of forests by 2030. This is estimated to sequester $0.48 \mathrm{Gt}$ of carbon dioxide. Activities such as the Initiative for Sustainable Landscapes (ISLA Kenya), supported through the Sustainable Trade Initiative and aiming to restore and conserve 60,000 hectares of the forest by 2030, should be promoted. To ensure sustainable ecosystem services flows, there is an urgent need for rehabilitation, and protection of Mau Kuresoi area is required due to encroachment. The Nyayo Tea Zones have made significant strides in this respect by establishing tea buffer zones, limiting encroachment into the remaining natural forest blocks of the Mau. Restoration of degraded areas is a key objective highlighted in the recently launched Green Economy Strategy and Implementation Plan (GESIP) 2016-2030.

\subsection{Ecosystem Monitoring}

A major shortcoming of the CCVA was the unavailability of data-for example, socioeconomic data at both temporal and spatial scales that could be adequately analyzed for each of the ecosystems. A socio economic and monitoring framework that is operationalized through mutually agreed sectoral monitoring plans could help to alleviate this problem and ensure future assessment outcomes are more representative of the ecosystems. As outlined in the 2016-2030 Kenya National Forest Program (MENR, 2016), Kenya is committed to participating in REDD+ as a climate-change mitigation mechanism. This process requires a system of adequately monitoring and reporting on the country's forest resources and other ecological and socioeconomic variables that describe the status of these water tower ecosystems. The ultimate goal of this monitoring is to develop better understanding of the effects of natural and human disturbances on these critical water tower ecosystems; guide development of ecosystem adaptation strategies at different scales; and develop scenarios for sustainable forest-resources management.

The use of carefully selected indicators ensures that a monitoring program 
addresses only the key variables associated with significant environmental effects, and it also improves monitoring communication and reporting processes. The water towers monitoring program should complement existing or emerging monitoring initiatives and learn from the challenges of other programs. The indicators can be monitored over time using internationally accepted indices and at time periods that capture the intent of the assessment. A comprehensive CCVA will require ecological and socioeconomic assessments, including habitat mapping; biodiversity and land-cover change monitoring; biomass estimation; greenhouse gas inventories; and human livelihoods. As indicated by Pfeifer et al. (2018), there is need for further analyses considering forest canopy structure along climate and other change variables, and this can only be achieved through systematic monitoring of the relevant ecosystem variables.

\subsection{Knowledge Transfer/Exchange in Community Participation}

The success of ecosystem management activities, including climate change resilience and adaptation, in the water towers will require active participation of local communities. Interaction and knowledge transfer between stakeholders are crucial, including local knowledge consideration. Linked to this, capacity building for local communities, through e.g. training activities on vulnerability assessments and ecosystem service valuation and mapping can improve understanding and subsequent adoption of adaptation activities. A fundamental aspect of the capacity to adapt to climate change is the integration of local knowledge systems based on long-term observation and experience.

\subsection{Socio Economic Vulnerability Understanding}

There are opportunities to improve on the results of our assessment. Our socioeconomic study focused on a limited number of indicators (due to data unavailability). Increased data and information can help to better understand the broader socioeconomic context within which communities living within the water tower ecosystems interrelate with the natural ecosystems and how threats to ecosystem integrity can be minimised to reduce both ecological and socio-economic vulnerability to future climate changes. Improvement in quantifying the socio-economic vulnerability, through integrating more indicators, can help to understand the trade-offs between ecosystem conservation and livelihood enhancement through utilization of products the same ecosystems provide.

\section{Conclusion}

1) The CCVA undertaken and reported here for the Mau, Cherangany, and Mt. Elgon Waters Towers highlights the wide range of effects climate change may have on both the Water Tower forest ecosystems and communities that depend on ecosystem services derived from these landscapes. While many of the effects elucidated here are based on imperfect knowledge from limited spatial and temporal data, there is a clear understanding that climate change will alter 
this status quo of the Water Tower ecosystems with far-reaching consequences on biodiversity, water resources, ecosystem service flows, and human well-being.

2) From the CCVA for the three ecosystems, there is significant evidence showing a decline in rainfall amounts in the Water Towers. This decline is accompanied by an increasing variability in the length of rainy seasons. Coupled with evident degradation of the ecosystems due to deforestation and land-use change, the ecosystems exhibit high vulnerability to climate change. Hotspots in these ecosystems, such as in Mau, include areas where there are high levels of charcoal production. The Water Towers provide an estimated 75 percent of the country's water resources. Reductions in rainfall are accompanied by water deficits for agricultural, industrial, and domestic purposes.

3) Decisions to address climate-related risks through increased adaptation and enhanced resilience for the Water Towers will depend, to a large extent, on economic, political, ecological, and societal factors. While these factors can be sitespecific, the assessment reported here highlights the need for concerted efforts in Kenya to adopt and implement green economy strategies defined in the GESIP (2016-2030) to maintain and improve forest cover, sustain ecosystem services flow, and ultimately increase the resilience of the Water Towers to climate change impacts.

4) Confronting the challenge of climate change presents opportunities for managers and policymakers to plan, manage for resilient landscapes, and ensure that the benefits that forests provide are sustained into the future. Success of the GoK Big Four Development Agenda is undoubtedly anchored in the country's ability to sustainably manage the Water Tower ecosystems, enhance their resilience to climate perturbations and ensure continued flow of valuable ecosystem services. This CCVA for the Water Towers, which can be enriched by local knowledge and site-specific information, will be a useful basis for land managers and policymakers to identify priority interventions in hotspots areas.

\section{Acknowledgements}

This work was made possible by the American people through the United States Agency for International Development (USAID) and the United States Forest Service (USFS) through the Participating Agency Program Agreement (PAPA). We acknowledge our partner organizations and agencies, including Kenya Meteorological Department, Kenya Forest Service, Kenya Wildlife Service, Water Resources Authority, among others, that permitted use of their datasets and resources, and therefore made this work possible. We thank the USAID Environment office team, especially Juniper Neill, the then Office Director for the Environment program and Beatrice Wamalwa, Deputy Director for supporting this work. We thank members of the local communities in Mau, Cherangany, and Mt. Elgon who took part in the surveys and focus group discussions that informed this assessment. Officials from the Environment offices of the Counties of Bomet, Bungoma, Elgeyo Marakwet, Kericho, Nakuru, Narok, Trans-Nzoia, 
and Uasin Gishu took active roles in meetings of the Advisory Group and their participation is sincerely acknowledged. Melody Schreiber (Freelance Editor and Writer) and Emily Kariuki (CIFOR Nairobi office) are thanked for their contributions by editing this report. Finally, we highly acknowledge the technical guidance provided by professional peers and specialists in various fields, not named here, but whose expert opinions informed this study.

\section{Conflicts of Interest}

The authors declare no conflicts of interest regarding the publication of this paper.

\section{References}

Boko, M., Niang, I., Nyong, A., Vogel, C., Githeko, A., Medany, M., Yanda, P. et al. (2007). Africa. In M. L. Parry, O. F. Canziani, J. P. Palutikof, P. J. van der Linden, \& C. E. Hanson (Eds.), Climate Change 2007: Impacts, Adaptation and Vulnerability. Contribution of Working Group II to the Fourth Assessment Report of the Intergovernmental Panel on Climate Change (pp. 433-467). Cambridge: Cambridge University Press.

Bonal, D., Burban, B., Stahl, C., Wagner, F., \& Hérault, B. (2016). The Response of Tropical Rainforests to Drought-Lessons from Recent Research and Future Prospects. Annals of Forest Science, 73, 27-44. https://doi.org/10.1007/s13595-015-0522-5

Bore, J. K. (2015). Tea Adaptation and Mitigation to Climate Change in Kenya (No. Presentation). Kericho, Kenya.

Carlos, L. E., \& Yoon, S. W. (2015). Local Vulnerability Indicators and Adaptation to Climate Change; A Survey (pp. 4-46). Washington DC: Inter-American Development Bank, Technical (Climate Change and Sustainability Division).

Choat, B., Jansen, S., Brodribb, T. J., Cochard, H., Delzon, S., Bhaskar, R., Zanne, A. E. et al. (2012). Global Convergence in the Vulnerability of Forests to Drought. Nature, 491, 752-755. https://doi.org/10.1038/nature11688

de Sherbinin, A. (2014). Spatial Climate Change Vulnerability Assessments: A Review of Data, Methods, and Issues (pp. 1-70).

de Sherbinin, A., Chai-Onn, T., Giannini, A., Jaiteh, M., Levy, M., Mara, V., Trzaska, S. et al. (2014). Mali Climate Vulnerability Mapping. USAID.

Deutsche Gesellschaft für Internationale Zusammenarbeit GIZ (2014). The Vulnerability Sourcebook (p. 171).

Endris, H. S., Lennard, C., Hewitson, B., Dosio, A., Nikulin, G., \& Panitz, H.-J. (2015). Teleconnection Responses in Multi-GCM Driven CORDEX RCMs over Eastern Africa. Climate Dynamics, 46, 2821-2846. https://doi.org/10.1007/s00382-015-2734-7

Endris, H. S., Omondi, P., Jain, S., Lennard, C., Hewitson, B., Chang'a, L., Tazalika, L. et al. (2013). Assessment of the Performance of CORDEX Regional Climate Models in Simulating East African Rainfall. Journal of Climate, 26, 8453-8475. https://doi.org/10.1175/JCLI-D-12-00708.1

FPP (2014). Forest Peoples Program Report. The Case of the Cherangany Hills, KenyaState Forest Protection Is Forcing People from Their Lands. http://www.iapad.org/wp-content/uploads/2016/01/141130 Cherangany Hills Case.pdf

Funk, C., Galu, G., Massawa, E., McCormick, S., Omondi, P., Sebina, E., White, L. et al. (2017). Climate Change Vulnerability, Impacts and Adaptation Assessment for East Africa. 
Funk, C., Peterson, P., Landsfeld, M., Pedreros, D., Verdin, J., Shukla, S., Michaelsen, J. et al. (2015). The Climate Hazards Infrared Precipitation with Stations-A New Environmental Record for Monitoring Extremes. Scientific Data, 2, Article ID: 150066. https://doi.org/10.1038/sdata.2015.66

Giorgi, F., Jones, C., \& Asrar, G. R. (2009). Addressing Climate Information Needs at the Regional Level: The CORDEX Framework.

Glick, P., Stein, B. A., \& Edelson, N. A. (2010). Scanning the Conservation Horizon: A Guide to Climate Change Vulnerability Assessment (p. 176). Washington DC: National Wildlife Federation.

GoK (2013). National Climate Change Action Plan 2013-2017. Nairobi: Government of Kenya.

IPCC, Intergovernmental Panel on Climate Change (2014). Climate Change 2014: Synthesis Report. Contribution of Working Groups I, II and III to the Fifth Assessment Report of the Intergovernmental Panel on Climate Change (151 p.). Geneva: IPCC.

Jiao, W., Zhang, L., Chang, Q., Fu, D., Cen, Y., \& Tong, Q. (2016). Evaluating an Enhanced Vegetation Condition Index (VCI) Based on VIUPD for Drought Monitoring in the Continental United States. Remote Sensing, 8, 224.

https://doi.org/10.3390/rs8030224

Kienberger, S., Lang, S., \& Zeil, P. (2009). Spatial Vulnerability Units-Expert-Based Spatial Modelling of Socio-Economic Vulnerability in the Salzach Catchment, Austria. Natural Hazards and Earth System Science, 9, 767-778. https://doi.org/10.5194/nhess-9-767-2009

KWTA (2019). Kenya Water Towers Agency Coordinated Environmental Protection. Policy Brief Mt. Elgon Water Tower. https://watertowers.go.ke/wp-content/uploads/2019/05/Kenya-Water-Towers-PolicyMt.-Elgon-Policy-30-4-2019 2.pdf

Livada, I., \& Assimakopoulos, V. D. (2006). Spatial and Temporal Analysis of Drought in Greece Using the Standardized Precipitation Index (SPI). Theoretical and Applied Climatology, 89, 143-153. https://doi.org/10.1007/s00704-005-0227-z

Locatelli, B., Brockhaus, M., Buck, A., \& Thompson, I. (2010). Forests and Adaptation to Climate Change: Challenges and Opportunities. In G. Mery, P. Katila, G. Galloway, R. I. Alfaro, M. Kanninen, M. Lobovikov, \& J. Varjo (Eds.), Forests and Society-Responding to Global Drivers of Change (pp. 21-42). Vienna: IUFRO.

Luck, J., Spackman, M., Freeman, A., Trebicki, P., Griffiths, W., Finley, K., \& Chakraborty, S. (2011). Climate Change and Diseases of Food Crops. Plant Pathology, 60, 113 121. https://doi.org/10.1111/j.1365-3059.2010.02414.x

Moret, W. (2014). Vulnerability Assessment Methodologies: A Review of the Literature (pp. 1-89).

Moss, R. H., Edmonds, J. A., Hibbard, K. A., Manning, M. R., Rose, S. K., van Vuuren, D. P., Wilbanks, T. J. et al. (2010). The Next Generation of Scenarios for Climate Change Research and Assessment. Nature, 463, 747-756. https://doi.org/10.1038/nature08823

Pfeifer, M., Gonsamo, A., Woodgate, W. et al. (2018). Tropical Forest Canopies and Their Relationships with Climate and Disturbance: Results from a Global Dataset of Consistent Field-Based Measurements. Forest Ecosystems, 5, 7. https://doi.org/10.1186/s40663-017-0118-7

PROVIA (2013). PROVIA Guidance on Assessing Vulnerability, Impacts and Adaptation to Climate Change.

Riahi, K., Rao, S., Krey, V., Cho, C., Chirkov, V., Fischer, G., Rafaj, P. et al. (2011). RCP 8.5-A Scenario of Comparatively High Greenhouse Gas Emissions. Climatic Change, 
109, 33-57. https://doi.org/10.1007/s10584-011-0149-y

Roy, D. C., \& Blaschke, T. (2015). A Grid-Based Approach for Spatial Vulnerability Assessment to Floods: A Case Study on the Coastal Area of Bangladesh.

Seswa, F. (2012). Assessment of Human Activities on the Vegetation of Tropical Rainforest in Kakamega County, Kenya. MSc Thesis.

Swanston, C., \& Janowiak, M. (2012). Forest Adaptation Resources: Climate Change Tools and Approaches for Land Managers (121 p.). USDA For. Serv., Gen. Tech. Rep. NRS-87, Northern Research Station Newtown Square, PA.

https://doi.org/10.2737/NRS-GTR-87

Tarus, G. K. (2017). Modelling Impacts of Climate Change on Tree Biomass and Distribution in Arabuko Sokoke Forest Reserve, Kenya (104 p.). MSc Thesis, Nairobi: University of Nairobi.

Thornton, P. K., Ericksen, P. J., Herrero, M., \& Challinor, A. J. (2014). Climate Variability and Vulnerability to Climate Change: A Review. Global Change Biology, 20, 3313 3328. https://doi.org/10.1111/gcb.12581

Tierney, J. E., Ummenhofer, C. C., \& deMenocal, P. B. (2015). Past and Future Rainfall in the Horn of Africa. Science Advances, 1, e1500682.

https://doi.org/10.1126/sciadv.1500682

UNEP (2008). Mau and Marmanet Forests. Economic and Socioeconomic Contributions, Current State and Trends.

UNEP (2012a). Kenya Integrated Forest Ecosystem Services. Technical Report.

UNEP (2012b). The Role and Contribution of Montane Forests and Related Ecosystem to the Kenyan Economy.

UNEP and GoK (2012). Water Towers, Forests and Green Economy; Outcome of the First High Level National Dialogue in Kenya.

Weis, S. W. M., Agostini, V. N., Roth, L. M., Gilmer, B., Schill, S. R., Knowles, J. E., \& Blyther, R. (2016). Assessing Vulnerability: An Integrated Approach for Mapping Adaptive Capacity, Sensitivity, and Exposure. Climatic Change, 136, 615-629.

https://doi.org/10.1007/s10584-016-1642-0

Willis, I., \& Fitton, J. (2016). A Review of Multivariate Social Vulnerability Methodologies: A Case Study of the River Parrett Catchment, UK. Natural Hazards and Earth System Sciences, 16, 1387-1399. https://doi.org/10.5194/nhess-16-1387-2016 